\title{
Validation of OCO-2 error analysis using simulated retrievals
}

\author{
Susan S. Kulawik ${ }^{1}$, Chris O’Dell ${ }^{2}$, Robert R. Nelson ${ }^{3, a}$, and Thomas E. Taylor ${ }^{2}$ \\ ${ }^{1}$ Bay Area Environmental Research Institute, Sonoma, CA, USA \\ ${ }^{2}$ Cooperative Institute for Research in the Atmosphere, Colorado State University, Fort Collins, CO, USA \\ ${ }^{3}$ Department of Atmospheric Science, Colorado State University, Fort Collins, CO, USA \\ anow at: Jet Propulsion Laboratory, California Institute of Technology, Pasadena, CA, USA
}

Correspondence: Susan S. Kulawik (susan.s.kulawik@nasa.gov)

Received: 18 October 2018 - Discussion started: 13 November 2018

Revised: 25 June 2019 - Accepted: 15 July 2019 - Published: 8 October 2019

\begin{abstract}
Characterization of errors and sensitivity in remotely sensed observations of greenhouse gases is necessary for their use in estimating regional-scale fluxes. We analyze 15 orbits of the simulated Orbiting Carbon Observatory-2 (OCO-2) with the Atmospheric Carbon Observations from Space (ACOS) retrieval, which utilizes an optimal estimation approach, to compare predicted versus actual errors in the retrieved $\mathrm{CO}_{2}$ state. We find that the nonlinearity in the retrieval system results in $\mathrm{XCO}_{2}$ errors of $\sim 0.9 \mathrm{ppm}$. The predicted measurement error (resulting from radiance measurement error), about $0.2 \mathrm{ppm}$, is accurate, and an upper bound on the smoothing error (resulting from imperfect sensitivity) is not more than $0.3 \mathrm{ppm}$ greater than predicted. However, the predicted $\mathrm{XCO}_{2}$ interferent error (resulting from jointly retrieved parameters) is a factor of 4 larger than predicted. This results from some interferent parameter errors that are larger than predicted, as well as some interferent parameter errors that are more strongly correlated with $\mathrm{XCO}_{2}$ error than predicted by linear error estimation. Variations in the magnitude of $\mathrm{CO}_{2}$ Jacobians at different retrieved states, which vary similarly for the upper and lower partial columns, could explain the higher interferent errors. A related finding is that the error correlation within the $\mathrm{CO}_{2}$ profiles is less negative than predicted and that reducing the magnitude of the negative correlation between the upper and lower partial columns from -0.9 to -0.5 results in agreement between the predicted and actual $\mathrm{XCO}_{2}$ error. We additionally study how the postprocessing bias correction affects errors. The biascorrected results found in the operational OCO-2 Lite product consist of linear modification of $\mathrm{XCO}_{2}$ based on specific retrieved values, such as the $\mathrm{CO}_{2}$ grad del $\left(\delta \nabla_{\mathrm{CO}_{2}}\right)$, ("grad del" is a measure of the change in the profile shape versus
\end{abstract}

the prior) and $\mathrm{dP}$ (the retrieved surface pressure minus the prior). We find similar linear relationships between $\mathrm{XCO}_{2} \mathrm{er}-$ ror and $\mathrm{dP}$ or $\delta \nabla_{\mathrm{CO}_{2}}$ but see a very complex pattern of errors throughout the entire state vector. Possibilities for mitigating biases are proposed, though additional study is needed.

\section{Introduction}

The Orbiting Carbon Observatory-2 (OCO-2) was launched in July 2014 and began providing science data in September 2014, with the goal of estimating $\mathrm{CO}_{2}$ with the "precision, resolution, and coverage needed to characterize sources and sinks of this important green-house gas." (Crisp et al., 2004). Validation of the ACOS/OCO-2 build 7 (referred to hereafter as v7) dataset (Eldering et al., 2017) versus measurements from the Total Carbon Column Network (TCCON) (Wunch et al., 2011) shows regional biases of about $0.5 \mathrm{ppm}$ and standard deviations of $1.5 \mathrm{ppm}$ (Wunch et al., 2017), though these errors are not entirely due to OCO-2 (TCCON and colocation errors also contribute). Biases are particularly concerning due to propagation of $\mathrm{CO}_{2}$ biases into flux biases (Basu et al., 2013; Chevallier et al., 2014; Feng et al., 2016). OCO-2 error analysis uses Rodgers (2000), which gives a statistical estimate of errors using first-order analysis that assumes that the forward model is linear and estimates errors due to smoothing, radiance measurement error, and interferent species. The predicted $\mathrm{XCO}_{2}$ errors for $\mathrm{v} 7 \mathrm{OCO}-2$ are typically $0.4 \mathrm{ppm}$ for ocean glint and $0.5 \mathrm{ppm}$ for nadir land, which underestimate the actual errors by at least a factor of 2 (Wunch et al., 2017). The cause of regional biases is thought to be underestimated 
interferent error or missing components of error analysis but is not well understood. Connor et al. (2016) found that missing physics in the forward model (e.g., more aerosol types, spectroscopy error, instrument error) leads to significantly larger posterior uncertainties than predicted by the current Atmospheric Carbon Observations from Space (ACOS) error analysis, using a purely linear error estimation framework. However, this study finds that nonlinear retrievals using this relatively simple simulation system (e.g., no spectroscopic errors, no instrument noise, consistent aerosol types between the true and retrieved states) also show a similar relationship between predicted and actual errors, with the actual error about twice the predicted one.

Cressie et al. (2016) estimates the size of second-order terms of the error analysis. The second-order terms contain derivatives of the averaging kernel, gain matrix, and Jacobians with respect to state parameters. Cressie et al. (2016) estimates that the errors resulting from second-order error analysis are on the order of $0.2 \mathrm{ppm}$, but this analysis was dependent on the states and sizes of deviations used to calculate the second-order derivatives. Cressie et al. (2016) found that second-order terms can cause both larger errors and biased results.

This paper explores the errors in the full physics retrieval system using a simulated system with no mismatches in the retrieval versus true state vector and no spectroscopy or instrument errors. The actual error covariance of (retrieved minus true) for this retrieval system is about twice the predicted errors. The linear analysis of Connor et al. (2016) does not explain the higher errors in this work, because the simulations in this work do not include unaccounted errors sources. Cressie et al. (2016) also does not explain the higher actual errors, because Cressie et al. (2016) estimates the secondorder error as about $0.2 \mathrm{ppm}$, whereas the unaccounted error is about $0.8 \mathrm{ppm}$ in this paper. In order to identify the source of the unaccounted error, actual errors are compared to the predicted linear errors for a series of setups.

The ACOS Level 2 (L2) full physics retrieval algorithm used to estimate $\mathrm{XCO}_{2}$ from OCO-2 employs optimal estimation using three near-infrared bands: (1) $0.76 \mu \mathrm{m}$ containing significant $\mathrm{O} 2$ absorption (O2 A band), (2) around $1.6 \mu \mathrm{m}$ containing weak $\mathrm{CO}_{2}$ absorption (weak $\mathrm{CO}_{2}$ band), and (3) near $2.1 \mu \mathrm{m}$ containing strong $\mathrm{CO}_{2}$ absorption (strong $\mathrm{CO}_{2}$ band). Prior to the main retrieval, a series of fast preprocessing steps are performed for quality analysis (primarily to screen out clouds) and to provide estimates of chlorophyll fluorescence (Frankenberg et al., 2016). Only soundings that are deemed sufficiently clear are selected to be processed by the computationally expensive L 2 retrieval. In the optimal estimation L2 retrieval used in this simulation, 45-46 retrieval parameters are simultaneously estimated, including $\mathrm{CO}_{2}$ volume mixing ratios (VMRs) at 20 pressures, albedos in three bands, four types of aerosols, meteorological parameters (temperature, water vapor, surface pressure), dis- persion (frequency offset), wind speed (ocean only), and fluorescence (land only).

The retrieved $\mathrm{CO}_{2}$ profile is then collapsed into a column, $\mathrm{XCO}_{2}$. Recent work has alternatively partitioned the information into two partial columns (Kulawik et al., 2017). Postprocessing quality screening and linear bias corrections based on various $\mathrm{L} 2$ retrieved parameters are then performed on $\mathrm{XCO}_{2}$. The corrections are based on the slope of $\mathrm{XCO}_{2}$ error versus different retrieved values, where the $\mathrm{XCO}_{2}$ error is estimated from retrieved $\mathrm{XCO}_{2}$ minus either (a) a constant value in the Southern Hemisphere, the Southern Hemisphere approximation; (b) values from surface-based observations from TCCON stations; (c) the mean of small areas (less than $1^{\circ}$ ); or (d) a multimodel mean (Mandrake et al., 2017). We study the effects of the postprocess bias correction in Sect. 4.3. The simulations in this paper differ from the operational retrieval in that the fluorescence true state is set to zero, although fluorescence is still retrieved; and amplitudes of spectral residual patterns are not retrieved; except for these minor differences, these simulated retrievals are identical to the operational $v 7$ retrievals. We refer the interested reader to O'Dell et al. (2018) for a full description of the operational retrieval, including retrieved variables and bias correction.

Simulation studies can be used to understand and probe retrieval results. There are many different ways to assess errors, listed here in order of increasing complexity and nonlinearity.

1. Linear estimates of errors, which assume moderate linearity of the retrieval system (Connor et al., 2008, 2016), useful for surveying impacts of different errors with linear assumptions.

2. Error estimates from nonlinear retrievals of simulated radiances using a fast, simplified radiative transfer, called the "surrogate model" (Hobbs et al., 2017). This system does not result in the discrepancy of larger actual versus predicted error.

3. Error estimates from nonlinear retrievals of simulated radiances generated using the operational L2 forward model, called the "simplified true state", which has the advantage that the true state is within the span of the retrieval vector and the linear estimate should be valid.

4. Error estimates from nonlinear retrievals of simulated radiances using a more complex and accurate radiative transfer model to generate the observed radiances (e.g., Raman scattering, polarization handling, surface albedo changes effects) and discrepancies between the true and retrieved state vectors (e.g., aerosol type mismatches between the true and retrieval state vector, albedo shape variations) (e.g., O’Dell et al., 2012).

This paper uses system (3), which makes it easier to interpret the actual versus expected performance of the retrieval system. System (3) was used because preliminary studies 
Table 1. Retrieved parameters in this simulation study.

\begin{tabular}{ll}
\hline Index & Parameter \\
\hline $1-20$ & $\begin{array}{l}20 \mathrm{CO}_{2} \text { volume mixing ratios (VMRs) } \\
\text { at } 20 \text { pressure levels from the surface to } \\
\text { top of the atmosphere (20). }\end{array}$ \\
\hline 21 & $\begin{array}{l}\text { Water vapor scaling factor. } \\
\text { Surface pressure. }\end{array}$ \\
23 & $\begin{array}{l}\text { Temperature profile offset. } \\
\text { Aerosol optical depth for four types. } \\
24,27,30,33,28,31,34\end{array}$ \\
\hline $26,29,32,35$ & $\begin{array}{l}\text { Aerosol pressure height for four types. } \\
\text { certainty is very tight). }\end{array}$ \\
\hline $36,38,40$ & $\begin{array}{l}\text { Albedo mean for three bands. } \\
\text { Albedo slope for three bands. }\end{array}$ \\
\hline $37,39,41$ & $\begin{array}{l}\text { Dispersion offset for three bands } \\
\text { (frequency offset). }\end{array}$ \\
\hline $42,43,44$ & $\begin{array}{l}\text { Wind speed (ocean). In the original files } \\
\text { this is index 36, but it was moved to } \\
\text { index 45 so that the albedo indices are } \\
\text { consistent between land and ocean. }\end{array}$ \\
\hline 45,46 & $\begin{array}{l}\text { Fluorescence (land). The true fluores- } \\
\text { cence is set to zero for these simula- } \\
\text { tions. }\end{array}$ \\
\hline
\end{tabular}

seemed to find that the performance of systems (3) and (4) was comparable (results not shown). Note that the observed radiance is generated with slightly different code than the retrieval system, but they are matched as closely as possible.

\section{Retrieval system}

\subsection{Description of the OCO-2 $\mathrm{L} 2$ retrieval algorithm and error diagnostics}

The ACOS optimal estimation approach is described in O'Dell et al. $(2012,2018)$ and Crisp et al. (2012). In this section we review the parameters in the retrieval vector and the equations for error estimates. The retrieved parameters for this simulation study are shown in Table 1.

All non- $\mathrm{CO}_{2}$ parameters are called "interferents", and the propagation of errors from these parameters into $\mathrm{CO}_{2}$ is called "interferent error".

The a priori covariance matrix for $\mathrm{CO}_{2}$ has the dimensions $20 \times 20$ and has strong correlations as shown in Fig. 2 of O'Dell et al. (2012). The $\mathrm{CO}_{2}$ a priori error is $48 \mathrm{ppm}$ at the surface, $12 \mathrm{ppm}$ in the midtroposphere, and $1.4 \mathrm{ppm}$ in the stratosphere. The larger variability near the surface allows more variability in the retrieved $\mathrm{CO}_{2}$ profile near the surface. However, in the ACOS retrieval, about $8 \%$ of the true midtropospheric $\mathrm{CO}_{2}$ variations are incorrectly attributed to surface variations based on the bias correction of $\delta \nabla_{\mathrm{CO}_{2}}(\mathrm{Ku}-$ lawik et al., 2017). The a priori errors for other parameters are all uncorrelated in the a priori covariance and can be found in the L2 product file.

The predicted errors, found in the OCO-2 L2 product as " $\mathrm{XCO}_{2}$ error_components", are based on the assumption that the nonlinear, iterative retrievals can be represented as a linear estimate (Connor et al., 2008; Rodgers, 2000), and shown in Eq. (1).

$\hat{\boldsymbol{v}}=\boldsymbol{v}_{\mathrm{a}}+\mathbf{A}_{v v}\left(\boldsymbol{v}_{\text {true }}-\boldsymbol{v}_{\mathrm{a}}\right)+\mathbf{A}_{v e}\left(\boldsymbol{e}_{\text {true }}-\boldsymbol{e}_{\mathrm{a}}\right)+\mathbf{G}_{v} \varepsilon$,

where

- $\hat{\boldsymbol{v}}$ is the retrieved $\mathrm{CO}_{2}$ profile, size $n \mathrm{CO}_{2}$ (20 for OCO2 ) - this variable is called " $u$ " in Connor et al. (2008), called " $v$ " here so as not to be confused with a different $U$ variable introduced later;

- $\boldsymbol{v}_{\mathrm{a}}$ is the a priori $\mathrm{CO}_{2}$ profile, size $n \mathrm{CO}_{2}$;

- $\boldsymbol{v}_{\text {true }}$ is the true $\mathrm{CO}_{2}$ profile, size $n \mathrm{CO}_{2}$;

- $\mathbf{A}_{v v}$ is the $n \mathrm{CO}_{2} \times n \mathrm{CO}_{2} \mathrm{CO}_{2}$ profile averaging kernel;

- $\mathbf{A}_{v e}\left(\boldsymbol{e}_{\text {true }}-\boldsymbol{e}_{\mathrm{a}}\right)$ is the cross-state error representing the propagation of error from non- $\mathrm{CO}_{2}$ retrieved parameters, $\boldsymbol{e}$ (aerosols, albedo, etc.), into retrieved $\mathrm{CO}_{2}$;

- $\boldsymbol{e}_{\mathrm{a}}$ is the a priori interferent value, size $n_{\text {interf }}-$ for this work, $n_{\text {interf }}$ is 26 (27) for ocean (land);

- $\boldsymbol{e}_{\text {true }}$ is the true interferent value, size $n_{\text {interf }}$;

- $\mathbf{A}_{v e}$ is size $n \mathrm{CO}_{2} \times n_{\text {interf }} ;$

- $\mathbf{G}_{v}$ is the gain matrix for $\mathrm{CO}_{2}$, size $n \mathrm{CO}_{2} \times n_{f}$, where $n_{f}$ is the number of spectral points; and

$-\varepsilon$ is the spectral error, also called "measurement error", size $n_{f}$.

The full gain matrix, $\mathbf{G}$, maps from spectral signals to retrieval parameter changes and is

$\mathbf{G}=\left(\mathbf{K}^{T} \mathbf{S}_{\varepsilon}^{-1} \mathbf{K}+\mathbf{S}_{\mathrm{a}}^{-1}\right)^{-1} \mathbf{K}^{T} \mathbf{S}_{\varepsilon}^{-1}$,

where $\mathbf{K}$ is the Jacobian (or Kernel) matrix, and $\mathbf{S}_{\varepsilon}$ is the error covariance of the spectral error, $\varepsilon$. Note that $\mathbf{G}$ is size $n \times n_{f}$, where $n=n \mathrm{CO}_{2}+n_{\text {interf }}$ is the total number of retrieved parameters. $\mathbf{K}$ is a matrix of derivatives giving the sensitivity of the radiance at each frequency to each retrieved parameter; e.g., for the $\mathrm{CO}_{2}$ parameter at $800 \mathrm{hPa}$,

$\mathbf{K}=\frac{\mathrm{dRadiance}}{\mathrm{d}\left(\mathrm{CO}_{2} @ 800 \mathrm{hPa}\right)}$.

An assumption of the ACOS retrieval system is that the Jacobians are fairly invariant during the retrieval process, as is the assumption for nearly all optimal estimation retrievals (see, e.g., Rodgers, 2000). 
The averaging kernel, $A$, is one of the most fundamental and useful quantities in Bayesian inversion theory. It describes the predicted linear dependence of the retrieved state on the true state and prior. The diagonal of the averaging kernel gives the degrees of freedom for signal for each retrieval parameter. The averaging kernel is calculated as

$\mathbf{A}=\mathbf{G K}$.

As will be shown in Sect. 3.1, we find that $\mathbf{K}_{\mathrm{CO}_{2}}$ varies depending on the retrieved state (indicating nonlinearity), which would result in an error in retrieved $\mathrm{CO}_{2}$ that is not captured in the predicted errors.

The linear estimate describes the response of the retrieval system to instrument errors and incorrect a priori inputs, based on the strengths of the Jacobians (representing sensitivity of the radiances to the retrieval state) and constraints (how much pressure is applied to parameters to stay near the a priori inputs). The linear estimate in Eq. (1) is used to estimate the errors, and for simulations, where we know all the inputs, it is useful to test each component of Eq. (1).

After an inversion is complete, the pressure weighting function $h$ (size $n \mathrm{CO}_{2}$ ) is used to convert the retrieved $\mathrm{CO}_{2}$ profile to $\mathrm{XCO}_{2}$ by tracking the contribution from each level to the column quantity:

$\mathrm{XCO}_{2}=\boldsymbol{h}_{\mathrm{XCO}_{2}}^{T} \hat{\boldsymbol{v}}$.

The predicted errors on the estimated $\mathrm{XCO}_{2}$ arise from three separate terms in Eq. (1):

1. $\mathbf{G}_{x} \varepsilon$ results from the errors on the measured radiances (measurement error),

2. $\mathbf{A}_{v v}\left(\boldsymbol{v}_{\text {true }}-\boldsymbol{v}_{\mathrm{a}}\right)$ results from both imperfect sensitivity and constraint choices (smoothing error), and

3. $\mathbf{A}_{v e}\left(\boldsymbol{v}_{\text {true }}-\boldsymbol{v}_{\mathrm{a}}\right)$ results from jointly retrieved species propagated into $\mathrm{CO}_{2}$ (interferent error).

The $\mathrm{CO}_{2}$ profile can also be partitioned into a lower and upper partial column (Kulawik et al., 2017). These can be calculated using equations similar to Eq. (5), with $h$ set for the lower partial column air mass (LMT) by zeroing out the upper 15 levels, and $h$ set for the upper partial column $(U)$ by zeroing out the lower 5 levels. In this work, the lower and upper partial columns are explored to try to understand the reasons behind the underpredicted $\mathrm{XCO}_{2}$ errors and the effect of the $\delta \nabla_{\mathrm{CO}_{2}}$ component of the bias correction.

One useful diagnostic is an estimate of how well the modeled radiances match the observed radiances for each of the three OCO-2 spectral bands:

$\chi_{\mathrm{rad}^{2}}[$ band $]=\frac{1}{n_{f}} \sum_{f}\left(\left(\boldsymbol{r}_{\mathrm{fit} f}-\boldsymbol{r}_{\mathrm{obs} f}\right) / \varepsilon_{f}\right)^{2}$,

where $\boldsymbol{r}_{\text {fit }}$ is the fit radiance, $\boldsymbol{r}_{\mathrm{obs}}$ is the observed radiance, and $\varepsilon$ is the radiance error.
In reality, Eq. (1) would contain many additional error terms that are not considered in these simulations, e.g., spectroscopy, instrument characteristics, aerosol mismatch errors (i.e., picking the wrong aerosol type to retrieve). These are discussed in detail in Connor et al. (2016) as linear error estimates. The results reported here only address errors in the full nonlinear retrieval system for the actual retrieved variables; they do not include errors from unincluded physics or other error sources (such as spectroscopy error). In the analysis presented in Sect. 3, each of the diagnostics given in Eqs. (1) through (5) will be used to examine the error estimates on the simulations and compared to previously published results on real OCO-2 data.

\subsection{Description of the simulated dataset}

The simulated dataset analyzed in this study is comprised of a set of realistic retrievals using the ACOS b3.4 version of the retrieval algorithm. It is a slightly modified version of that described in detail in O'Dell et al. (2012) (which discussed b2.9) and described more fully in O'Dell et al. (2018). Table 2 shows the most important changes to the L2 retrieval algorithm between $\mathrm{b} 2.9$ and $\mathrm{b} 3.4$.

Although newer versions of the OCO-2 L2 algorithm exist (currently b8 as of time of writing), the work presented here was initially begun prior to the launch of OCO-2 in July 2014. In addition, certain tests, where the L2 true state is directly related to the retrieval vector, were simplified by using the older version of the retrieval algorithm which contains a less complicated aerosol scheme. In the older L2 algorithm versions (pre-B3.5), also used in this work, the state vector for all soundings always included the same four aerosol types: cloud water, cloud ice, Kahn 1 (a mixture of coarse- and fine-mode dust aerosols), and Kahn 2 (carbonaceous-mode aerosols) (described more in Nelson et al., 2016). Both Kahn 1 and 2 types contain some sulfate and sea salt aerosols as well. Newer versions of the OCO-2 L2 retrieval include a more complicated scheme in which each sounding includes water and ice, and they pick the two most likely aerosol types based on a MERRA monthly climatology for the particular sounding location. The aerosol fits use a Gaussian-shaped vertical profile for each of the four types, as described in O'Dell et al. (2018).

Inputs to the b3.4 L2 retrieval algorithm include simulated $\mathrm{L} 1 \mathrm{~b}$ radiances and meteorology (taken from ECMWF) that were generated using the CSU/CIRA simulator (O'Brien et al., 2009). The simulator is driven by satellite two-line elements which are used to provide the satellite time and position. The code calculates relevant solar and viewing geometry and polarization and takes surface properties from MODIS. Only a single day's worth of orbits (15 orbits on 17 June 2012) at reduced temporal sampling ( $1 \mathrm{~Hz}$ instead of the operational $3 \mathrm{~Hz}$ ) and with only one footprint per frame (instead of the operational eight) is presented in this work. This yields approximately 2700 soundings per orbit, totaling 
Table 2. Updates in the simulated retrieval system since O'Dell et al. (2012).

\begin{tabular}{lll}
\hline B2.10 changes & B3.3 changes & B3.4 changes \\
\hline 1) Gaussian aerosol profiles & 1) Residual fitting & 1) Ocean surface parameterization \\
2) Sigma pressure levels & 2) Reduced p_surf prior uncertainty & 2) Update weak $\mathrm{CO}_{2}$ spectral range \\
3) Update to prior $\mathrm{CO}_{2}$ profile & 3) Prior AOD $=0.05$ & 3) Spectroscopy update \\
4) Spectroscopy updates & 4) Spectroscopy update & \\
5) Correction to $\mathrm{XCO}_{2} \mathrm{AK}$ & 5) Fluorescence fit land gain $\mathrm{H}$ (GOSAT) & \\
\hline
\end{tabular}

about 40000 soundings. Unlike real OCO-2 viewing modes (see Crisp et al., 2017), the simulations were generated with nadir viewing over land and glint viewing over water. Our simulations do not include nadir-water, glint-land, or target mode simulations, which are additional observation modes used in real OCO-2 data (Crisp et al., 2017). The spectral error for these simulations assumes Gaussian random noise, following the OCO-2 noise parameterization as described in Rosenberg et al. (2017).

Although the simulations do include realistic clouds and aerosols from a CALIPSO/CALIOP (Winker et al., 2010) monthly climatology, the radiative transfer portion of the simulator code allows clouds and aerosols to be switched off, making it easy to generate clear-sky radiances used in this research. The OCO-2 instrument model, described in detail in O'Brien et al. (2009), was used to add realistic instrument noise to the radiances prior to running the L2 retrieval for the noiseless simulations. The operational OCO-2 dispersion, instrument line shape (ILS), and polarization sensitivity were used to sample the top-of-atmosphere radiances. The same solar model as used in the operational retrieval was used in the L1b simulations. In addition, the A-band preprocessor code described in Taylor et al. (2016) was run on the cloudysky L1b simulations to provide realistic cloud screening prior to running the L2 retrieval. It is important to test the system from end to end with radiances containing a variety of cloud conditions, because the cloud screening is never $100 \%$ accurate, sometimes letting through cloudy cases, and because quality flags can sometimes flag cloudy cases being as good quality without clouds.

This error analysis ideally would use the exact same forward model in both the L1b simulations and the L2 retrieval algorithm, as our analysis assumes that Eq. (1) should be valid, without errors from forward model differences. However, in reality these two code bases are very similar but not identical. For example, the number of vertical levels within the two code bases differs. Reasonable attempts were made to put the L1b simulations on the same footing with the L2 forward model, but minor model mismatches may remain. We do not believe these minor differences affect our primary results.

Our goal in this work is to compare linearly predicted vs. actual errors in $\mathrm{XCO}_{2}$, specifically in terms of three primary contributions to the retrieval error discussed above: measure-
Table 3. Configurations used in this work.

\begin{tabular}{|c|c|c|c|}
\hline Case & $\begin{array}{l}\text { Measurement } \\
\text { error }\end{array}$ & $\begin{array}{l}\text { Clouds }+ \\
\text { aerosols }\end{array}$ & Comment \\
\hline (a) & No & No & Smoothing only \\
\hline (b) & No & Yes & Smoothing + interferent \\
\hline (c) & Yes & Yes & $\begin{array}{l}\text { Smoothing }+ \text { interferent }+ \\
\text { measurement error }\end{array}$ \\
\hline (d) & No & Yes & Different water prior/initial \\
\hline
\end{tabular}

ment, smoothing, and interferent error. Several different configurations were used to allow the estimation of the true error for each of these error components, as shown in Table 3. The clear results have no clouds or aerosols in the true state; however, the retrieval is free to insert clouds into the retrieved state (and given that aerosols are retrieved as $\ln (\mathrm{AOD})$, the retrieved states is never fully aerosol-free).

Results from different configurations are intercompared to validate the individual measurement, smoothing, and retrieval errors. These predicted errors are compared to the true errors resulting from nonlinear retrievals, which are the retrieved minus true values.

\subsection{Postprocessing quality screening}

Similar to retrievals from real observations, the simulated retrieval results need screening to remove cloudy scenes (e.g., see O'Brien et al., 2016; Polonsky et al., 2014). Because prescreening is not perfect, the $\mathrm{XCO}_{2}$ estimates from some soundings are of low quality, even if they converge. Postprocessing screening is handled through calculation of quality flags, taken from Table 5 of Polonsky et al. (2014). These flags are (a) $\chi_{\mathrm{rad}^{2}}$ (defined in Eq. 6) $<2$ for cases with measurement error or $\chi_{\mathrm{rad}^{2}}<1$ for cases with no measurement error, (b) retrieved aerosol optical depth $<0.2$, and (c) degrees of freedom $>1.6$ (degrees of freedom are defined near Eq. 4). The three bands are averaged to calculate the $\chi_{\mathrm{rad}^{2}}$ for the scene.

Table 4 shows the effects of applying postprocessing quality screening for the different configurations from Table 3. The results are separated into land and ocean scenes; approximately one-third pass postprocessing quality screening for cloudy cases; about $80 \%$ pass postprocessing qual- 
Table 4. Number of cases for each configuration. The clouds in true $=$ yes cases contain many fewer soundings than no clouds because of prescreening. The no. good is from postprocessing screening.

\begin{tabular}{llrrl}
\hline & $\begin{array}{l}\text { Clouds } \\
\text { in true }\end{array}$ & No. & $\begin{array}{r}\text { No. good } \\
\text { (postscreening) }\end{array}$ & $\begin{array}{l}\text { Configuration } \\
\text { (from Table 3) }\end{array}$ \\
\hline Land (nadir) & No & 12097 & 10229 & $\mathrm{a}$ \\
Ocean (glint) & No & 14265 & 11468 & $\mathrm{a}$ \\
Land (nadir) & Yes & 3445 & $868 / 869 / 768$ & $\mathrm{c} / \mathrm{b} / \mathrm{d}$ \\
Ocean (glint) & Yes & 1560 & $679 / 674 / 620$ & $\mathrm{c} / \mathrm{b} / \mathrm{d}$ \\
\hline
\end{tabular}

ity screening for cloud-free cases. For configuration (c) in Table 3 (simulations that include clouds), $11 \%$ and $28 \%$ of cases passing prescreening for ocean and land, respectively. Post-processing screening identifies $25 \%$ and $43 \%$ of cases for ocean and land, respectively. These are low compared to OCO-3 simulation studies (Eldering et al., 2019), where $25 \%-30 \%$ of cases passed prescreening and $50 \%-$ $70 \%$ of cases passed postscreening. Some of the quality flags used for the OCO-3 studies (particularly the preprocessing flags) are not available in our study, so it is hard to directly compare throughput. The lower throughput suggests that the cloud cases or other aspects of this study were harder than the OCO-3 simulation studies.

\subsection{Comparisons of retrieved values to true}

Table 5 shows $\mathrm{XCO}_{2}$ biases and errors for the different configurations from Table 3. The quantities calculated for Table 5 are the bias (the mean retrieved minus true values) and standard deviation (the square root of the second moment of the retrieved minus true difference). These quantities indicate the overall quality of the results for each configuration. The results in Table 5 are sorted by standard deviation. The worst result by far is the cloudy case with no postprocessing screening. This has $\sim 10 \mathrm{ppb}$ error for land and $\sim 3 \mathrm{ppm}$ error for ocean. Ocean generally does better than land, postprocessing screening generally does better than no screening, and clear cases do better than cloudy cases. The addition of measurement error has a negligible effect on standard deviation for this testing. The bold entry in Table 5 represents the most realistic real-life case (+ measurement error, + clouds, + postprocessing screening). This has $0.8 \mathrm{ppm}$ standard deviation for land and $0.7 \mathrm{ppm}$ standard deviation for ocean.

In the screened data, the main concern is the $-0.5 \mathrm{ppm}$ bias in the clear land retrieval. We have seen this in other sets of simulations and it is an unresolved issue at this time. Recently we did find a minor bug in the simulator code that caused a small mismatch between the water vapor profile used to calculate the $\mathrm{L} 1 \mathrm{~b}$ radiances and that written to the meteorology file that is then used in the L2 retrieval. It is possible that other minor bugs of this nature are driving the clear-sky bias, with errors mitigated by clouds in the cloudy cases.
Figure 1 shows a scatter plot of the retrieved versus true $\mathrm{XCO}_{2}$ (both with the a priori subtracted). The lower panels in Fig. 1 show the histogram of differences, which range from about -1.25 to $+1.5 \mathrm{ppm}$ for land and -1.5 to $+2 \mathrm{ppm}$ for water soundings. Bias correction, discussed in Sect. 4.3, further improves the land results by $0.1 \mathrm{ppm}$ in the bias and standard deviation as seen in Table 5 but does not improve ocean results. The standard deviations of (retrieved - true) (green dashed line) and (retrieved - linear estimate) (blue dashed line) are very similar; the linear estimate does not estimate the results any better than 0.7 to $0.9 \mathrm{ppm}$ and gives an estimate of the nonlinearity.

For real OCO-2 v8 data, comparisons to TCCON for single-observation land nadir and ocean glint have errors of 1.0 and $0.8 \mathrm{ppm}$, respectively (Kulawik et al., 2019a), meaning that the real errors are comparable to these simulated data. Real OCO-2 data have a systematic error on the order of 0.5-0.6 ppm (Wunch et al., 2017; Kulawik et al., 2019a). Correlated biased errors are seen in real OCO-2 data, with correlations in time, e.g., $\sim 60 \mathrm{~d}$ (Kulawik et al., 2019a), at small spatial scales, e.g., $<1^{\circ}$ (Worden et al., 2017), and at medium spatial scales, e.g., 5-10 (Kulawik et al., 2019a). Although this dataset cannot probe a seasonally dependent bias, as it covers only $1 \mathrm{~d}$ of observations, it can be used to probe spatial patterns of the biases. However, note that probing very small spatial patterns will be difficult to see because of the small number of data processed in comparison to real OCO-2. A plot showing the spatial pattern of retrieved minus true is shown in Fig. 2a, which shows a high bias near the Equator and a low bias near the poles. Figure $2 b$ shows the difference between true $\mathrm{XCO}_{2}$ and $\mathrm{XCO}_{2}$ with the OCO-2 averaging kernel. The overall spatial pattern in panel (a) is not affected by the application of the averaging kernel, which makes sense because the averaging kernel effect is $\sim 0.2 \mathrm{ppm}$, whereas the differences are on the order of $0.9 \mathrm{ppm}$. An analysis of the correlation scale length of (retrieved minus true) $\mathrm{XCO}_{2}$ finds a correlated error of $0.3 \mathrm{ppm}$ and the full width at half maximum in the bias of $\sim 3^{\circ}$, which is similar to the correlated error of $0.4 \mathrm{ppm}$ and scale length of $\sim 5-10^{\circ}$ found in Kulawik et al. (2019a). The simulated data have an accurate meteorology (temperature, winds, etc.) that drives the simulated true states, but the cloud and aerosol spatial structures are not very accurate, so that the spatial scales are not expected to be identical between this simulated dataset and real OCO-2 data. This analysis shows that correlated biases exist in simulated data and that simulated data are useful for exploring the characteristics and, even more importantly, the cause of regional biases.

\section{Validation of errors and nonlinearity}

In this section the different error components that were introduced in Sect. 2.1 are isolated as much as possible to evaluate each one separately. The averaging kernel and Jacobians, in- 
Table 5. Mean bias and standard deviation between retrieved and true, sorted by standard deviation. The bold entries are the nominal cases most closely simulating actual OCO-2 retrievals.

\begin{tabular}{lllllrr}
\hline $\begin{array}{l}\text { Case from } \\
\text { Table } 3\end{array}$ & $\begin{array}{l}\text { Land/ } \\
\text { ocean }\end{array}$ & $\begin{array}{l}\text { Clouds } \\
\text { in true }\end{array}$ & $\begin{array}{l}\text { Postprocessing } \\
\text { screening }\end{array}$ & $\begin{array}{l}\text { Meas. } \\
\text { error }\end{array}$ & $\begin{array}{r}\text { Mean } \\
\text { bias }\end{array}$ & $\begin{array}{r}\text { Standard } \\
\text { deviation }\end{array}$ \\
\hline (a) & Ocean & No & Yes & No & -0.1 & 0.4 \\
(a) & Land & No & Yes & No & -0.5 & 0.4 \\
(a) & Ocean & No & No & No & -0.3 & 0.6 \\
(a) & Land & No & No & No & -0.5 & 0.7 \\
(b) & Ocean & Yes & Yes & No & 0.1 & 0.7 \\
(c) & Ocean & Yes & Yes & Yes & $\mathbf{0 . 1}$ & $\mathbf{0 . 7}$ \\
(b) & Land & Yes & Yes & No & 0.2 & 0.8 \\
(c) & Land & Yes & Yes & Yes & $\mathbf{0 . 2}$ & $\mathbf{0 . 8}$ \\
(b) & Ocean & Yes & No & No & -0.6 & 2.7 \\
(b) & Land & Yes & No & No & -2.3 & 10.3 \\
\hline
\end{tabular}
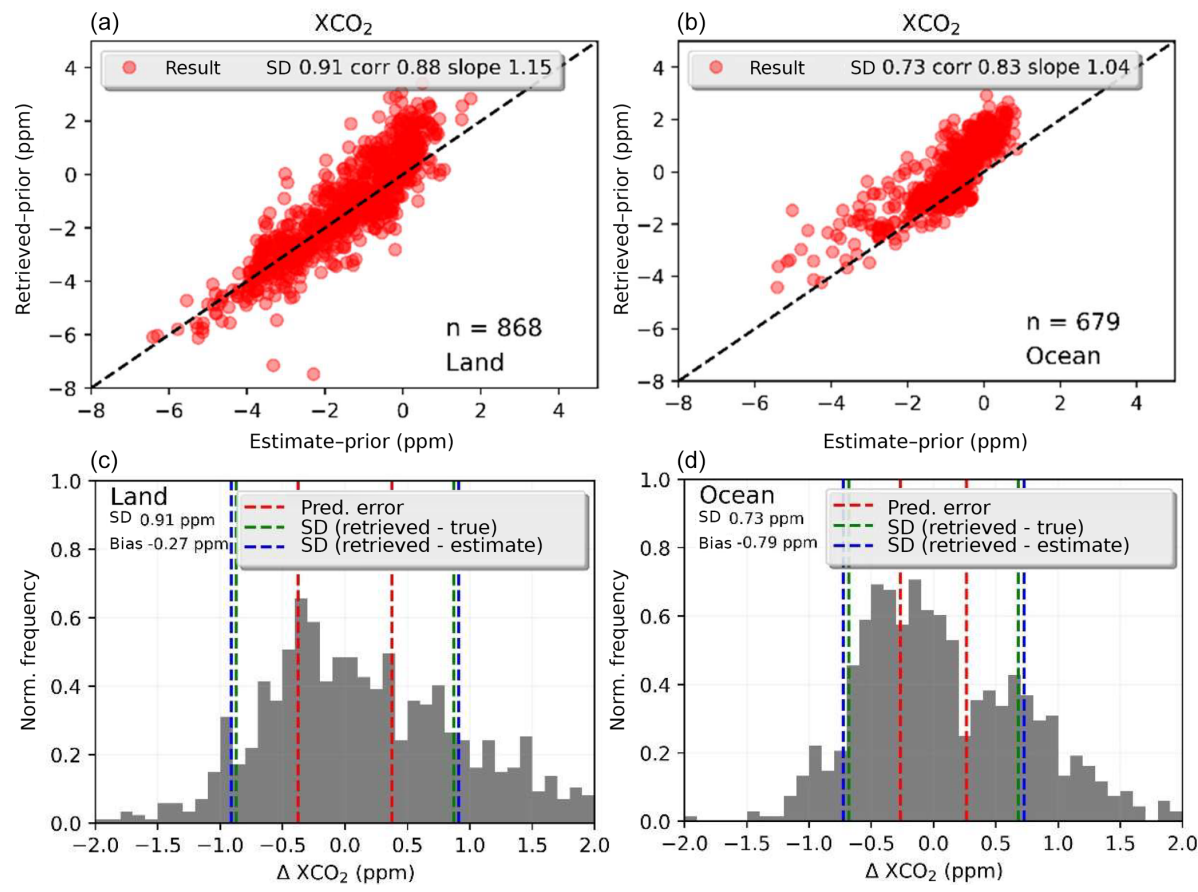

Figure 1. Scatter plots of $\mathrm{XCO}_{2}$ difference from the prior for retrieved versus true on the simulated data. This corresponds to dataset (c) with clouds and measurement error; postprocessing screening applied for land (a, c) and ocean (b, d), with $1: 1$ plots shown in panels (a) and (b); and histogram of the differences in (c) and (d).

troduced in Sect.2.1, are used as diagnostics. In addition, the linearity, or lack thereof, of the system is explored.

\subsection{System linearity}

To test the system linearity the linear estimate, using Eq. (1) and discussed in Sect. 2.1 is compared to the nonlinear retrieval result. The inputs to Eq. (1) include the instrument noise (if on), a priori covariance, and Jacobians at the final retrieved state. Table 6 shows the results for cases passing postprocessing quality screening, clouds, and no measurement error (Table 3, case d) using (1) the first two terms on the right side of Eq. (1) (i.e., only the $\mathrm{CO}_{2}$ part of the averaging kernel) or (2) all of Eq. (1) (i.e., utilizing the interferent terms). The last term of Eq. (1) is not used for the noise-free case. The bottom entry in Table 6 , shows the retrieved vs. true $\mathrm{XCO}_{2}$ (without averaging kernel applied). The comparisons of retrieved $\mathrm{XCO}_{2}$ versus the linear estimate have biases between 0.2 and $0.9 \mathrm{ppm}$ and standard deviation between 0.6 and $0.9 \mathrm{ppm}$. The bias is worse if the full averaging kernel is used. Looking through parameter by parameter, the band 3 albedo average causes most of the large bias for the full averaging kernel for ocean. The difference between the linear 


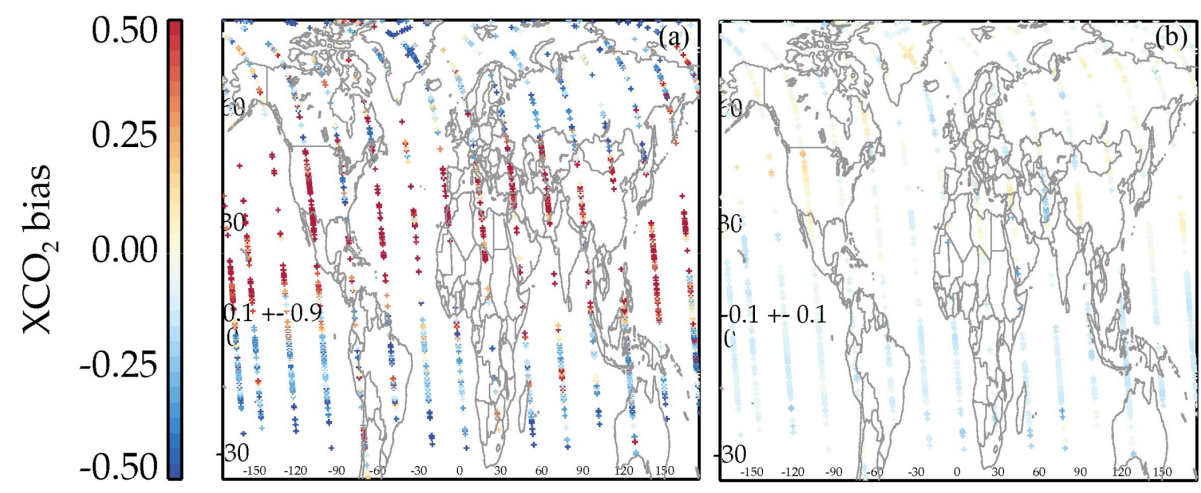

Figure 2. (a) Spatial pattern of $\mathrm{XCO}_{2}$ retrieved minus true for case (b) from Table 3 (cloudy but no measurement error), with quality screening. Panel (b) shows the difference between true $\mathrm{XCO}_{2}$ with the OCO-2 averaging kernel applied minus true $\mathrm{XCO}_{2}$.

Table 6. Difference of linear estimate versus nonlinear retrieval, noise-free, cloud, quality-screened cases. SD denotes standard deviation.

\begin{tabular}{lrrrr}
\hline & $\begin{array}{r}\text { Land } \\
\text { bias }\end{array}$ & $\begin{array}{r}\text { Land } \\
\text { SD }\end{array}$ & $\begin{array}{r}\text { Ocean } \\
\text { bias }\end{array}$ & $\begin{array}{r}\text { Ocean } \\
\text { SD }\end{array}$ \\
\hline Predicted & 0 & 0.3 & 0 & 0.2 \\
Retrieved vs. $\mathrm{CO}_{2} \mathrm{AK}$ & -0.2 & 0.8 & -0.2 & 0.6 \\
Retrieved vs. full AK & -0.4 & 0.8 & -0.9 & 0.8 \\
Retrieved vs true & 0.2 & 0.9 & 0.1 & 0.7 \\
\hline
\end{tabular}

estimate and the nonlinear retrieval is an estimate of the nonlinear error in the retrieval system.

Another test of the system linearity is the consistency of the sensitivity of the system to changes in $\mathrm{XCO}_{2}$; i.e., how constant are the $\mathrm{XCO}_{2}$ Jacobians (defined in Eq. 3)? For example, consider if the $\mathrm{XCO}_{2}$ Jacobian weakens when an interferent, e.g., call it interferent no. 1 , increases. If interferent no. 1 is larger than its true value, the $\mathrm{XCO}_{2}$ Jacobian will be weaker than the true $\mathrm{XCO}_{2}$ Jacobian. If the $\mathrm{XCO}_{2}$ Jacobian is weaker than the true Jacobian, then more $\mathrm{XCO}_{2}$ is needed to account for the radiance differences observed, resulting in a positive bias in $\mathrm{XCO}_{2}$. This would result in a positive correlation in the errors of interferent no. 1 and $\mathrm{XCO}_{2}$. This error correlation would not be predicted by the linear error analysis because the linear error analysis assumes that the Jacobians do not vary. This could explain the stronger error correlations seen.

To calculate an error resulting from varying Jacobians requires calculating second-order terms, like dJacobian[ $\left.\mathrm{XCO}_{2}\right] / \mathrm{d}\left[\mathrm{H}_{2} \mathrm{O}\right.$ scaling]. Cressie et al. (2016) calculated nonlinear errors, using second-order error analysis, and found errors on the order of $0.2 \mathrm{ppm}$, which would not fully explain the discrepancy between the predicted and true errors either in the simulation studies or real data.

Figure 3 shows the Jacobian magnitude (the $\mathrm{XCO}_{2} \mathrm{Ja}$ cobian averaged over all frequencies) for $\mathrm{XCO}_{2}$ versus re- trieved band 2 albedo slope. The Jacobians for the lower (LMT) and upper $(U)$ partial columns (described in Kulawik et al., 2017, and Sect. 2.1) are also plotted, and both partial columns vary the same way, e.g., same slope signs; i.e., the nonlinear interferent error would be positively correlated between the two partial columns.

The right panel of Fig. 3 compares the Jacobian magnitude between matched results from configuration (c) and (d) in Table 3 for land cases with postprocessing screening. The $\mathrm{CO}_{2}$ Jacobian magnitude difference is up to $-4 \%$ for case (c) minus (d) and is correlated with the difference in retrieved $\mathrm{H}_{2} \mathrm{O}$ scaling with correlation -0.75 . Other parameters that had strong correlations $(>0.4)$ are aerosol water pressure $(0.55)$, aerosol ice pressure $(0.43)$, surface pressure (0.41). Mapping this correlation to an error in retrieved $\mathrm{XCO}_{2}$ would require the calculation of second-order Jacobians as in Cressie et al. (2016) and then mapping this into an error in $\mathrm{XCO}_{2}$. A crude way to estimate the $\mathrm{XCO}_{2}$ error resulting from these Jacobian differences is to consider the completely linear case, where radiance is equal to $\mathbf{K}$ multiplied by $\mathrm{XCO}_{2}$. In this case, a $+1 \%$ error in the Jacobian would result in $\mathrm{a}-1 \%$ error in $\mathrm{XCO}_{2}$, to fit the radiance. So, the variations in the $\mathrm{XCO}_{2}$ Jacobians that are seen could explain the $0.8 \mathrm{ppm} \mathrm{XCO}_{2}$ differences from the linear estimate.

\subsection{Measurement error}

To validate the measurement error, results from runs with and without noise (cases (c) and (b) from Table 3) are analyzed. The standard deviation of the $\mathrm{XCO}_{2}$ difference between the runs (true error) was compared to the predicted measurement error. The two runs, which both have clouds and other interferents, as well as smoothing errors, are assumed to be identical other than one having measurement error added. The runs are compared after quality screening, which was described in Sect. 2.4.

Figure 4 shows the baseline and predicted measurement error. For land nadir, the average error is $0.35 \mathrm{ppm}$ and the average predicted is $0.29 \mathrm{ppm}$. For ocean glint, the average 

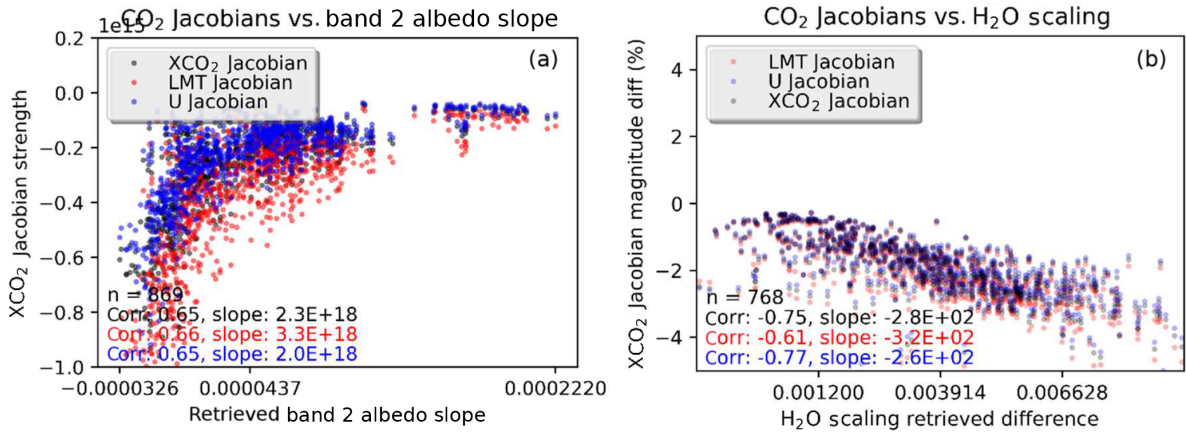

Figure 3. $\mathrm{XCO}_{2}$ (black), lower $\mathrm{CO}_{2}$ partial column (red), and upper $\mathrm{CO}_{2}$ partial column (blue) Jacobian band-averaged magnitude versus interferent parameters. (a) shows $\mathrm{CO}_{2}$ magnitude versus retrieved band 2 albedo slope, using the configuration (b) from Table 3; (b) shows the $\mathrm{CO}_{2}$ Jacobian magnitude difference (in percent) for matched cases from run (b) and (d) versus differences in retrieved $\mathrm{H}_{2} \mathrm{O}$ scaling.
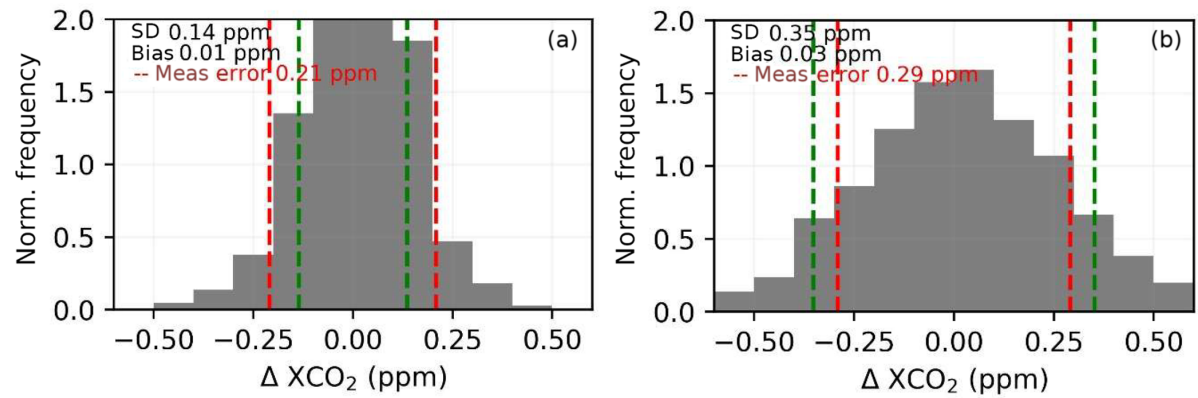

Figure 4. Histogram of difference between $\mathrm{XCO}_{2}$ with noise on and noise off for ocean (a) and land (b), cases (b) and (c) from Table 3 .

Table 7. Error versus averaging for measurement error.

\begin{tabular}{lrr}
\hline $\begin{array}{l}n \\
\text { (number averaged) }\end{array}$ & $\begin{array}{r}\text { Error land } \\
(\mathrm{ppm})\end{array}$ & $\begin{array}{r}\text { Error ocean } \\
(\mathrm{ppm})\end{array}$ \\
\hline 1 & 0.35 & 0.14 \\
2 & 0.25 & 0.10 \\
3 & 0.20 & 0.08 \\
9 & 0.12 & 0.05 \\
\hline
\end{tabular}

error is $0.14 \mathrm{ppm}$ and the average predicted error is $0.21 \mathrm{ppm}$. The bias difference between the runs with and without noise was $0.01 \mathrm{ppm}$ for ocean and $0.03 \mathrm{ppm}$ for land nadir.

The predicted error ranged from 0.14 to $0.70 \mathrm{ppm}$ for land and 0.12 to $0.35 \mathrm{ppm}$ for ocean. The correlation between the predicted error and the absolute value of the error is 0.27 for land and 0.08 for ocean, so the scene-to-scene variations in the predicted error are not very useful.

Adjacent observations are averaged, and then the error of this averaged quantity is calculated. If the error reduces with the square root of the number of observations averaged, then the error is a random, not correlated, error. A random error is highly desirable for assimilation and other uses. For land nadir the error is shown in Table 7.

If the error is random, then the $n=9$ result should be onethird of the error for the $n=1$ result, and this is what is found. Similarly for ocean, the error for $n=9$ is $1 / 3$ of the $n=1$ error. The simulated data do not have the data density of actual OCO-2 data, so while averaging in close proximity would likely behave similarly, there is some uncertainty.

In summary, for these simulated cases, the measurement error is overpredicted for land by $0.06 \mathrm{ppm}$ and overpredicted for ocean by $0.07 \mathrm{ppm}$, but the measurement error appears to average randomly and does not introduce a bias.

\subsection{Smoothing error}

Smoothing error occurs when the averaging kernel deviates from the identity matrix, and it is calculated using the averaging kernel, the true state, and the prior state. The smoothing error terms from Eq. (1) are

$\boldsymbol{v}_{\text {true_ak }}=\boldsymbol{v}_{\mathrm{a}}+\mathbf{A}_{x x}\left(\boldsymbol{v}_{\text {true }}-\boldsymbol{v}_{\mathrm{a}}\right)$.

Here, $v$ represents the $\mathrm{CO}_{2}$ profile, which is converted to $\mathrm{XCO}_{2}$ using Eq. (5). To validate the smoothing error, the nonlinear retrieved $\mathrm{XCO}_{2}$ is compared to the linear estimate, $\left(\mathrm{XCO}_{2}\right)_{\text {true_ak }}=\boldsymbol{h}_{\mathrm{XCO}_{2}}{ }^{T} \boldsymbol{v}_{\text {true_ak }}$, from Eq. (7), and to $\left(\mathrm{XCO}_{2}\right)_{\text {true }}=\boldsymbol{h}_{\mathrm{XCO}_{2}}{ }^{T} \boldsymbol{v}_{\text {true }}$. The linear estimate should compare better to the nonlinear retrieval. Run (a) from Table 3 is used, which does not contain clouds in the true state (i.e., limited interferent error) and does not have a measurement error in the observed radiances. 
The predicted smoothing error is $0.12 \mathrm{ppm}$ for ocean glint and $0.16 \mathrm{ppm}$ for land nadir. Comparison between retrieved $\mathrm{XCO}_{2}$ and true has a mean bias of $0.0 \mathrm{ppm}$ for ocean and a mean bias of 0.46 bias for land (retrieved $\mathrm{XCO}_{2}$ is $0.46 \mathrm{ppm}$ lower than true). The standard deviation is $0.33 \mathrm{ppm}$ for land and $0.35 \mathrm{ppm}$ for ocean.

Comparison of the retrieved $\mathrm{XCO}_{2}$ versus $\left(\mathrm{XCO}_{2}\right)_{\text {true_ak }}$ or $\left(\mathrm{XCO}_{2}\right)_{\text {true }}$ yielded the same biases and standard deviations (within $0.02 \mathrm{ppm}$ ). Therefore, the use of the OCO-2 averaging kernel and prior for comparisons, using Eq. (7), does not improve the comparison quality versus OCO-2. This analysis suggests modelers would get similar quality results whether or not the OCO-2 averaging kernel is applied during assimilation. However, a previous study by Wunch et al. (2011) found that for comparisons to TCCON, if the averaging kernel is not applied, it leads to $0.2 \mathrm{ppm}$ seasonal biases. The current analysis shows that it does not do harm to apply Eq. (7) but that it does not help either, with the caveat that the simulated data do not cover different seasons.

\subsection{Interferent error}

Previous studies by Merrelli et al. (2015) and O'Brien et al. (2016) have found that clouds and aerosols can contribute errors larger than predicted. We look at the relationship between errors in retrieved interferents versus errors in $\mathrm{XCO}_{2}$ and the prediction of the relationship as characterized by the averaging kernel.

The error in $\mathrm{XCO}_{2}$ from the interferent term of Eq. (1), multiplied by the pressure weighting function, $h$, estimates the propagation of interferent error into $\mathrm{XCO}_{2}$, shown in Eq. (8).

$\mathrm{XCO}_{2}$ interferent error $=\boldsymbol{h}_{\mathrm{XCO}_{2}}^{T} \mathbf{A}_{x v}\left(\boldsymbol{v}_{\mathrm{a}}-\boldsymbol{v}_{\text {true }}\right)$

This equation predicts that the interferent will only have an impact if the prior state is different than the true state and that the impact will be proportional to the prior state minus the true state difference, with the constant of proportionality provided by the off-diagonal averaging kernel, $\mathbf{A}_{x v}$. Many of the interferents, e.g., $\mathrm{H}_{2} \mathrm{O}$ Scaling, start at their true values for this simulation and therefore are predicted to have no impact on $\mathrm{XCO}_{2}$ errors. Yet, large correlations in errors are seen when comparing $\mathrm{XCO}_{2}$ errors and interferent errors, e.g., $\mathrm{H}_{2} \mathrm{O}$ Scaling error. Taking the expected standard deviation of the $\mathrm{XCO}_{2}$ interferent error from Eq. (8) gives the predicted interferent error, which averages $0.2 \mathrm{ppm}$ for case (b) from Table 3.

We look at (retrieved minus true $\mathrm{XCO}_{2}$ ) versus (prior minus true interferent) or (retrieved minus true interferent) in Fig. 5, using run (b) from Table 3, which has clouds but no measurement error. The red line shows $h_{\mathrm{XCO}_{2}}^{T} A_{x v}\left(v_{\mathrm{a}}-v_{\text {true }}\right)$, the predicted relationship between the $\mathrm{XCO}_{2}$ error and the prior minus true difference. For both band 2 albedo slope, left, and $\mathrm{H}_{2} \mathrm{O}$ scaling, right, there is no predicted relationship, but a strong correlation is seen. This could be explained by the results from Sect. 3.1, showing that the $\mathrm{XCO}_{2}$ Jacobian strength varies with the retrieved albedo or retrieved water, whereas the error analysis assumes that the Jacobian strength does not vary.

Figure 6 shows the predicted versus true errors, including correlations. The true error is calculated from Error $_{i j}=$ mean $\left((\text { retrieved }- \text { true })_{i}(\text { retrieved }- \text { true })_{j}\right)$ for all cases with good quality. The true errors are much larger and show more correlations than predicted. Both matrices are normalized using the equation

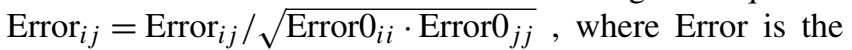
error covariance of interest and Error0 is the predicted error covariance. To further analyze the interferent error, we looked at the diagonal terms of the error covariance and the correlations to $\mathrm{XCO}_{2}$ in Table 8. In order for the error correlations between $\mathrm{XCO}_{2}$ and interferents to be assessed, the $\mathrm{CO}_{2}$ profile is mapped to $\mathrm{XCO}_{2}$ using Eq. (5). Table 8 shows the predicted and true errors for all interferents, for all good-quality land cases. The error factor (EF) is calculated as

$\mathrm{EF}=\sqrt{\left(\sigma_{\text {true }}^{2}+\text { bias }_{\text {true }}^{2}\right) / \sigma_{\text {predicted }}^{2}}$,

where the predicted standard deviations come from the predicted errors and the true standard deviation and bias come from the true errors. The error factor is found to be greater than 1 for almost all parameters.

Another useful diagnostic of interferent error is the predicted error correlation between each interferent and $\mathrm{XCO}_{2}$, calculated by

Correlation $_{i j}=$ Error $_{i j} / \sqrt{\text { Error }_{i i} \cdot \text { Error }_{j j}}$,

which can be compared to the actual error correlation. Table 8 shows that for most interferents both the errors and the correlations are underpredicted. The parameters that are both underpredicted and significantly correlated $(>0.25)$ to $\mathrm{XCO}_{2}$ errors are shown in bold.

The true effect of interferent error on $\mathrm{XCO}_{2}$ can be crudely estimated by the actual slope of $\mathrm{XCO}_{2}$ error (not shown in Table 8s, but the actual slope is shown in Fig. 5) multiplied by the interferent error. This estimate cannot distinguish between correlation and causation. The standard deviation of this estimate is shown as the last column of Table 8 ("Impact on $\mathrm{XCO}_{2}$ "). The interferent error estimated with a more simplified surrogate model was much smaller in Hobbs et al. (2017).

\section{Postprocessing bias corrections}

Postprocessing analysis of real ACOS OCO-2 retrieval results has uncovered linear relationships between $\mathrm{XCO}_{2}$ error and various parameters such as the retrieved surface pressure, liquid water optical depth, and $\delta \nabla_{\mathrm{CO}_{2}}$ (an estimate of the profile curvature) (Wunch et al., 2011). Similar correlations have been found between the above parameters and the 

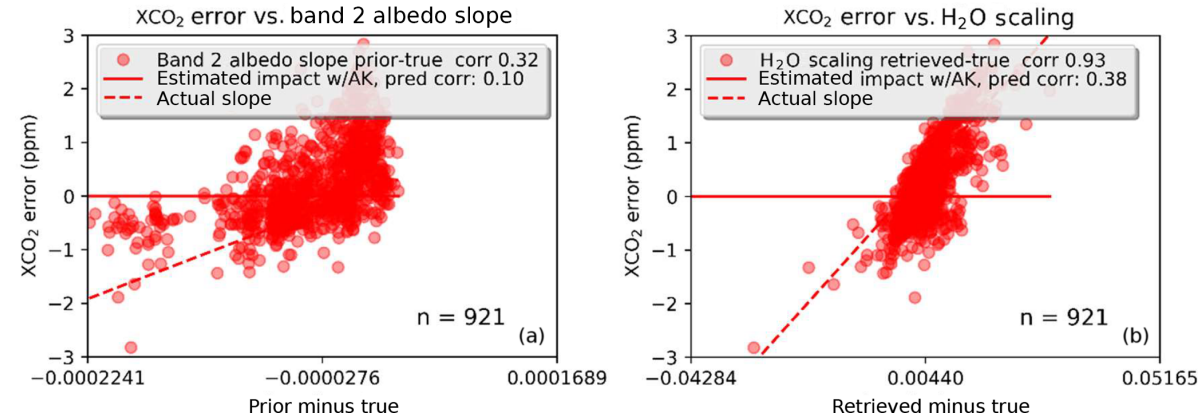

Figure 5. Predicted (red line) and true error (red dots) for two interferents: band 2 albedo slope (a) and $\mathrm{H}_{2} \mathrm{O}$ scaling (b).

Table 8. Predicted and actual errors for interferents and correlations between interferents and $\mathrm{XCO}_{2}$ for simulated land retrievals for case (b) from Table 3. Bold values are those parameters with interferent errors larger than predicted and large actual correlations to $\mathrm{XCO}_{2}$ error (absolute value larger than 0.25 ).

\begin{tabular}{llrrrrrr}
\hline & & $\begin{array}{r}\text { Pred. } \\
\text { error }\end{array}$ & $\begin{array}{r}\text { Actual } \\
\text { error }\end{array}$ & $\begin{array}{r}\text { Error } \\
\text { factor }\end{array}$ & $\begin{array}{r}\text { Pred. } \\
\text { corr. }\end{array}$ & $\begin{array}{r}\text { Actual } \\
\text { corr. }\end{array}$ & $\begin{array}{r}\text { Impact on } \\
\text { XCO }\end{array}($ ppm) \\
\hline Met & H O scaling & $\mathbf{0 . 0 0 3}$ & $\mathbf{0 . 0 0 5} \pm \mathbf{0 . 0 0 4}$ & $\mathbf{5}$ & $\mathbf{0 . 3 5}$ & $\mathbf{0 . 9 3}$ & $\mathbf{1 . 2}$ \\
Met & Surface pressure & 0.5 & $-0.67 \pm 1.02$ & 3 & -0.38 & -0.02 & 0.0 \\
Met & Temperature offset & $\mathbf{0 . 0 4}$ & $\mathbf{0 . 2 5} \pm \mathbf{0 . 2 2}$ & $\mathbf{9}$ & $\mathbf{0 . 1 7}$ & $\mathbf{0 . 4 4}$ & $\mathbf{0 . 6}$ \\
Aerosol & Aerosol ice OD & $\mathbf{0 . 0 0 2}$ & $-\mathbf{0 . 0 2} \pm \mathbf{0 . 2 1}$ & $\mathbf{1 0 1}$ & $\mathbf{0 . 0 3}$ & $\mathbf{0 . 8 1}$ & $\mathbf{1 . 1}$ \\
Aerosol & Aerosol ice pressure & 0.09 & $0.03 \pm 0.28$ & 3 & -0.01 & 0.22 & 0.3 \\
Aerosol & Aerosol ice width & 0.01 & $0.01 \pm 0.01$ & 2 & -0.00 & 0.13 & 0.2 \\
Aerosol & Aerosol Kahn 1 OD & $\mathbf{0 . 0 1}$ & $-\mathbf{5 . 0} \pm \mathbf{0 . 8}$ & $\mathbf{4}$ & $-\mathbf{0 . 3 6}$ & $-\mathbf{0 . 3 9}$ & $\mathbf{0 . 5}$ \\
Aerosol & Aerosol Kahn 1 pressure & 0.3 & $0.3 \pm 0.4$ & 1 & 0.08 & -0.10 & 0.1 \\
Aerosol & Aerosol Kahn 1 width & 0.01 & $0.04 \pm 0.08$ & 9 & -0.00 & -0.19 & 0.3 \\
Aerosol & Aerosol Kahn 2 OD & 0.01 & $-5.0 \pm 0.8$ & 2 & 0.32 & -0.02 & 0.0 \\
Aerosol & Aerosol Kahn 2 pressure & $\mathbf{0 . 4}$ & $\mathbf{0 . 7} \pm \mathbf{0 . 5}$ & $\mathbf{2}$ & $-\mathbf{0 . 0 2}$ & $\mathbf{0 . 2 6}$ & $\mathbf{0 . 3}$ \\
Aerosol & Aerosol Kahn 2 width & 0.01 & $0.1 \pm 0.09$ & 17 & 0.00 & 0.18 & 0.2 \\
Aerosol & Aerosol water OD & 0.008 & $-5.9 \pm 1.0$ & 7 & -0.06 & -0.15 & 0.2 \\
Aerosol & Aerosol water pressure & 0.4 & $0.7 \pm 0.5$ & 3 & -0.01 & -0.06 & 0.1 \\
Aerosol & Aerosol water width & 0.01 & $0.09 \pm 0.03$ & 9 & 0.00 & -0.13 & 0.2 \\
Albedo & Band 1 albedo ave. & $\mathbf{0 . 0 0 0 8}$ & $-\mathbf{0 . 0 0 0 2} \pm \mathbf{0 . 0 0 3}$ & $\mathbf{3}$ & $\mathbf{0 . 1 9}$ & $-\mathbf{0 . 5 0}$ & $\mathbf{0 . 7}$ \\
Albedo & Band 1 albedo slope & $1 \times 10^{-6}$ & $1 \times 10^{-6} \pm 1 \times 10^{-6}$ & 3 & -0.26 & -0.10 & 0.1 \\
Albedo & Band 2 albedo ave. & $\mathbf{0 . 0 0 0 6}$ & $-\mathbf{0 . 0 0 2} \pm \mathbf{0 . 0 0 4}$ & $\mathbf{7}$ & $\mathbf{0 . 1 9}$ & $-\mathbf{0 . 5 4}$ & $\mathbf{0 . 7}$ \\
Albedo & Band 2 albedo slope & $1 \times 10^{-7}$ & $2 \times 10^{-6} \pm 2 \times 10^{-6}$ & 8 & 0.10 & 0.20 & 0.3 \\
Albedo & Band 3 albedo ave. & 0.0007 & $-0.001 \pm 0.005$ & 7 & 0.04 & -0.22 & 0.3 \\
Albedo & Band 3 albedo slope & $\mathbf{1} \times \mathbf{1 0}-\mathbf{6}$ & $\mathbf{0 e}-\mathbf{6} \pm \mathbf{2} \times \mathbf{1 0}-\mathbf{6}$ & $\mathbf{3}$ & $\mathbf{0 . 1 4}$ & $-\mathbf{0 . 3 6}$ & $\mathbf{0 . 5}$ \\
\hline
\end{tabular}

lower partial column (Kulawik et al., 2017). The standard operational procedure that has been adopted by the ACOS algorithm team for both OCO-2 and GOSAT data is to perform a bias correction of the estimated $\mathrm{XCO}_{2}$ based on the linear correlations of the difference in $\mathrm{XCO}_{2}$ compared to various truth metrics with certain retrieved parameters. In this section, we look specifically at the behavior of $\delta \nabla_{\mathrm{CO}_{2}}$ (defined in Sect. 4.1) and dP (defined in Sect. 4.2) bias correction in the simulated system. The purpose of the analysis of this section is to answer the following questions.

1. Do the bias correction for $\mathrm{dP}$ and $\delta \nabla_{\mathrm{CO}_{2}}$ behave similarly in the simulation system to the real OCO-2 retrievals?
2. What is the effect of bias correction on $\mathrm{CO}_{2}$ errors?

The bias correction is determined using this simulated dataset and then applied to the same dataset, which is somewhat circular, since the true is both used to determine the bias correction and to check the bias correction, but it is important to know whether the relationships exist. For example, what causes the spatial patterns seen in the bias in Fig. 2.

\subsection{The retrieved profile gradient}

$\delta \nabla_{\mathrm{CO}_{2}}$ is defined as delta[20]-delta[13], where delta is the retrieved $\mathrm{CO}_{2}$ profile minus the prior $\mathrm{CO}_{2}$ profile, [20] is the surface level, and [13] is seven levels above the surface, i.e., $0.63 *$ (surface pressure). $\delta \nabla_{\mathrm{CO}_{2}}$ represents the gradient of the 

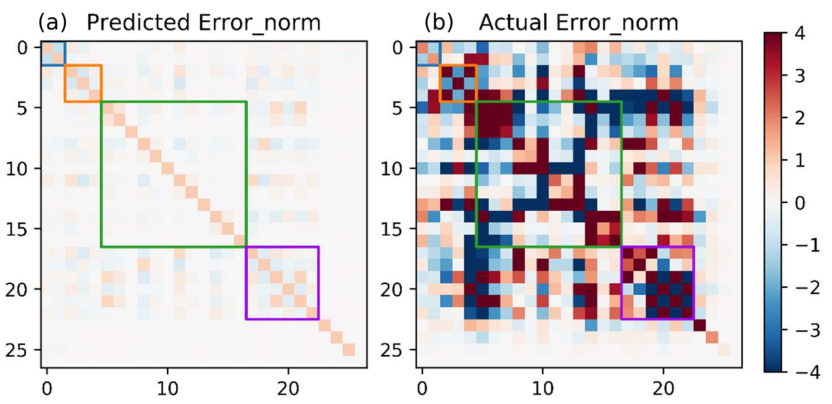

Figure 6. Predicted and true errors. (a) shows the predicted error covariance matrix, for the retrieval parameters listed in Table 1, with the $\mathrm{CO}_{2}$ profile collapsed into two parameters (LMT and $U$ partial columns). The blue, orange, green, and purple boxes contain $\mathrm{CO}_{2}$, metrological, aerosol, and albedo parameters, respectively. Both matrices are normalized by the diagonal of the predicted errors.

retrieved $\mathrm{CO}_{2}$ profile that differs from the prior. It has been found that the slope of $\mathrm{XCO}_{2}$ error versus $\delta \nabla_{\mathrm{CO}_{2}}$ varies depending on the a priori covariance that is used in the retrieval system, with a more evenly varying covariance having less dependency of $\mathrm{XCO}_{2}$ error versus $\delta \nabla_{\mathrm{CO}_{2}}$ (O'Dell, unpublished data). The standard OCO-2 constraint is very loose at the surface (e.g., with $50 \mathrm{ppm}$ a priori variability) and tighter in the midtroposphere (with $\sim 10 \mathrm{ppm}$ a priori variability). Most $\mathrm{CO}_{2}$ variability does occur near the surface near the primary sources and sinks, but the a priori constraint used in the retrieval algorithm would favor variations at the surface even in cases when the variations occur at a higher level due to the weighting due to the prior covariance.

Figure 7 shows errors in $\mathrm{XCO}_{2}, \mathrm{LMT}$ (the lower tropospheric column, approximately up through $2.5 \mathrm{~km}$ ), and $U$ (the upper partial column, approximately from $2.5 \mathrm{~km}$ through the top of the atmosphere) (LMT and $U$ are described in Kulawik et al., 2017, and Sect. 2.1) versus $\delta \nabla_{\mathrm{CO}_{2}}$ for configuration (b). In the simulated retrievals, the values of the slope of delta $\mathrm{XCO}_{2}$ versus $\delta \nabla_{\mathrm{CO}_{2}}$ are -0.001 and -0.008 for land and ocean, respectively. It is clear that there are significant errors in the partitioning between the lower (LMT) and upper $(U)$ partial columns that are correlated to $\delta \nabla_{\mathrm{CO}_{2}}$. The slope of LMT versus $\delta \nabla_{\mathrm{CO}_{2}}$ is 0.23 and 0.22 for land and ocean, respectively, and -0.07 and -0.08 for $U$ land and ocean, respectively. For real ACOS-GOSAT (B3.5) data, Kulawik et al. (2017) found a slope of 0.39 for land and 0.31 for ocean for LMT and -0.11 and -0.09 for $U$ land and ocean, respectively, which are similar values as seen in this simulated dataset.

These results naturally lead to the following question: what is the effect of placing $\mathrm{CO}_{2}$ at the wrong pressure level? The mean Jacobian for the $U$ partial column (upper 15 layers) is only about $60 \%$ (0.62) of the mean value for the lowermost four layers. Therefore, a molecule in the LMT partial column is equivalent to about 1.6 molecules in the upper par- tial column. Therefore, a molecule mistakenly placed in the lower four layers and moved to the upper layers in the postprocessing step needs to be exchanged for 1.6 molecules in the upper partial column to have the same impact on the radiances at the new level. At $\delta \nabla_{\mathrm{CO}_{2}}$ of 35, for land, LMT is high by $\sim 8.4 \mathrm{ppm}$. For an even exchange, moving $8.4 \mathrm{ppm}$ from the LMT partial column to the $U$ partial column results in +2.5 ppm in the $U$ partial column only from the effects of air mass (because the $U$ partial column has more air mass; $=8.4 \mathrm{ppm} * .23 \mathrm{LMT}$ air mass $/ 0.77 U$ air mass). Considering the difference in sensitivity, and multiplying by 1.6 , this corresponds to $+4.0 \mathrm{ppm}$ in the $U$ partial column. The net effect on $\mathrm{XCO}_{2}$ of this bias correction is the sum of the partial columns times the air mass, $-8.4 * .23+4.0 * .77=1.1 \mathrm{ppm}$. This is at $\delta \nabla_{\mathrm{CO}_{2}}$ of 35 , so that would mean that the slope for $\mathrm{XCO}_{2}$ error versus $\delta \nabla_{\mathrm{CO}_{2}}$ is 0.031 . For real OCO-2 v7 data, the slope of $\mathrm{XCO}_{2}$ error versus $\delta \nabla_{\mathrm{CO}_{2}}$ is +0.0280 and -0.077 for land and ocean, respectively (Mandrake et al., 2017). This analysis explains a positive slope in $\mathrm{XCO}_{2}$ versus $\delta \nabla_{\mathrm{CO}_{2}}$ but would not explain a negative slope. The negative slope would result from additional correlations or errors acting in addition to this effect.

\subsection{The retrieved surface pressure}

The quantity $\mathrm{dP}$ is the difference between retrieved and prior surface pressure and is used as a postprocessing bias correction for OCO-2. In this section, we explore results from $\mathrm{dP}$ in the simulated dataset to try to understand why bias correction based on this parameter is useful.

Although it is typically assumed that the surface pressure is determined solely from the $\mathrm{O} 2 \mathrm{~A}$ band, the strong and weak $\mathrm{CO}_{2}$ bands also contribute information. For land nadir, averaged over cases passing postprocessing quality screening, the band-averaged Jacobian strengths in the weak and strong $\mathrm{CO}_{2}$ bands relative to the $\mathrm{O} 2 \mathrm{~A}$ band are 0.2 and 0.4 , respectively. Based on the surface pressure Jacobian and the spectral error, a value of $-2 \mathrm{hPa}$ will create a spectral bias 0.2 times the size of the spectral error in the $\mathrm{O} 2 \mathrm{~A}$ band, which, because it is a correlated error, will be an additive error over the band.

Figure 8 shows the actual error covariances and biases for three different subsets of run (d): $\mathrm{dP}<-2 \mathrm{hPa},-1<\mathrm{dP}<$ $1 \mathrm{hPa}$ (nominal cases), and $\mathrm{dP}>1.5 \mathrm{hPa}$. The errors shown are normalized by the predicted error, using the equation $\mathbf{E} i j=\mathbf{E} i j / \sqrt{(\mathbf{E} 0 i i \cdot \mathbf{E} 0 j j)}$, where $\mathbf{E}$ is the error covariance of interest and $\mathbf{E} 0$ is the predicted error covariance. A diagonal value of 1 means that the actual error is the same as predicted, and a diagonal value of 4 represents an actual error that is twice $(\sqrt{(4)})$ as large as predicted. The errors and error correlations are much larger than predicted for many parameters. In addition, the $\mathrm{CO}_{2}$ parameters show less correlation with other parameters for the nominal case. Also note that the nominal case has less saturation, meaning less errors and correlations. 

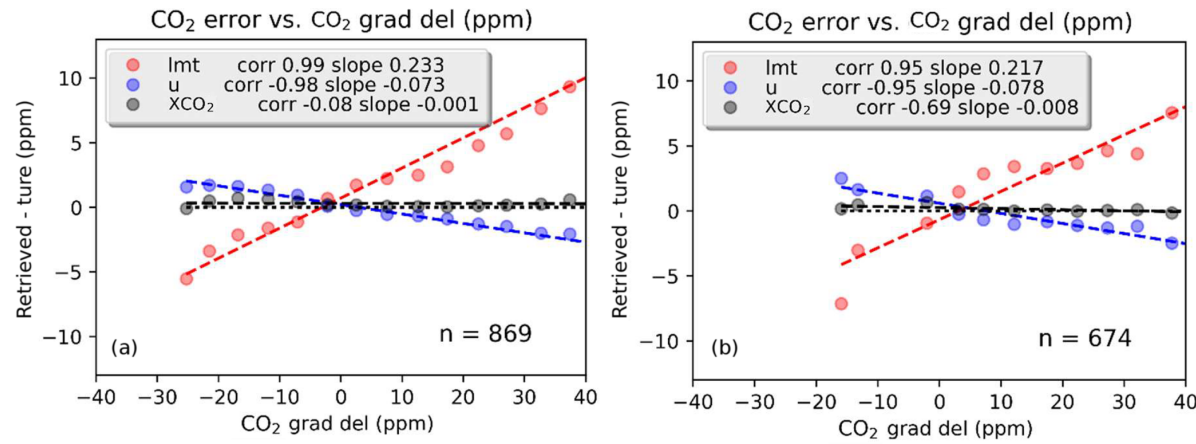

Figure 7. Error in retrieved $\mathrm{CO}_{2}$ for $\mathrm{XCO}_{2}$ (black), upper partial column, $U$ (blue), and lower partial column LMT (red) versus $\delta \nabla_{\mathrm{CO}}$ for ocean (a) and land (b).

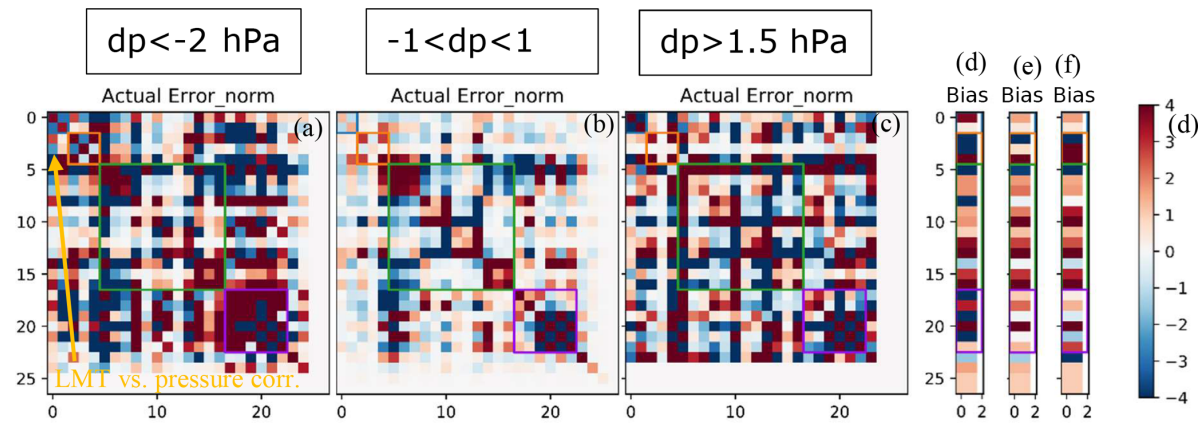

Figure 8. Normalized actual error covariances and biases of retrieved parameters for $\mathrm{dP}<-2 \mathrm{hPa}(\mathbf{a}, \mathbf{d}),-1<\mathrm{dP}<1 \mathrm{hPa}(\mathbf{b}, \mathbf{e})$, and $\mathrm{dP}>1.5 \mathrm{hPa}$ (c, f) using the configuration from Table 3 (d) for land/cloudy. The purple box surrounds the albedo parameters, the green box surrounds aerosol parameters, the red box surrounds metrological parameters, and the blue box surrounds the $\mathrm{CO}_{2}$ fields, which have been collapsed into lower and upper partial columns. The errors are normalized by the predicted errors (which are shown in Fig. 5). The arrow in panel (a) shows correlation between LMT and surface Pressure, which is negative (also see Fig. 9b below).

Next we looked at the possibility of screening incorrect surface pressure results using $\chi_{\mathrm{rad}^{2}}$ (defined in Eq. 6). To do this, we used land cases for configuration (c) in Table 3 (simulations that include clouds), and looked at $\chi_{\mathrm{rad}}{ }^{2}$ for two groups: (group 1) $\mathrm{dP}<-2$ and (group 2) $-1<\mathrm{dP}<0$. The cases with $\mathrm{dP}<-2$ had $0.04,0.01$, and 0.06 higher reduced $\chi_{\mathrm{rad}}{ }^{2}$ in the three bands, respectively. Although the $\mathrm{dP}<-2$ case fit the spectra worse there was too much overlap to distinguish between these cases solely from $\chi_{\mathrm{rad}}{ }^{2}$.

The albedo errors and correlations (purple box) particularly stand out, with correlations with many retrieved parameters. The albedo terms are, in order, O2 A-band mean, O2 Aband slope, weak mean, weak slope, strong mean, and strong slope. Based on the $\mathrm{O} 2 \mathrm{~A}$-band mean albedo and the surface pressure Jacobians, a change in retrieved surface pressure of $-2 \mathrm{hPa}$ can be compensated for by a change in the albedo on the order of -0.001 , with this analysis based on band averages, and not necessarily implying a good fit. However, this analysis indicates that very minute changes in the surface albedo (on the order of $0.1 \%$ ) can compensate for moderate sized errors in the retrieved surface pressure. The exact relationship can be better studied by examining the radiative transfer and looking at how the final transmission of sunlight relates to both the total amount of atmospheric absorption and the surface albedo.

Errors in the retrieved $\mathrm{XCO}_{2}$, lower partial column (LMT), and upper partial columns $(U)$ are plotted versus the error in surface pressure in Fig. 9, which all show moderate $(R=$ $0.63)$ to strong $(R=-0.98)$ correlations. The bias found in this work for this simulated dataset for the $\mathrm{XCO}_{2}$ bias versus $\mathrm{dP}$ is -0.23 for land and 0.15 for ocean. We can compare these to the OCO- $2 \mathrm{v} 7$ biases of -0.3 for land and -0.08 for ocean. Note that for the simulated data, the prior surface pressure is set to the true, so (surface pressure - prior) is the same as (surface pressure - true). The bias correction factors are found in Table 4 of the $\mathrm{v} 7$ bias correction documentation.

The retrieval system must match the mean photon path length for the $\mathrm{O} 2$ A-band channel using retrieved parameters like surface pressure, albedo, water, temperature, aerosol pressure heights, and aerosol optical depths. Also note that the $\mathrm{O}_{2}$ volume mixing ratio (VMR) is fixed and not retrieved. Mean photon path length increases with higher albedo and aerosol optical depth (Palmer et al., 2001). Additionally, moving aerosols lower in the atmosphere increases mean photon path length, because light scattered by the aerosol travels farther, and a larger surface pressure will increase 

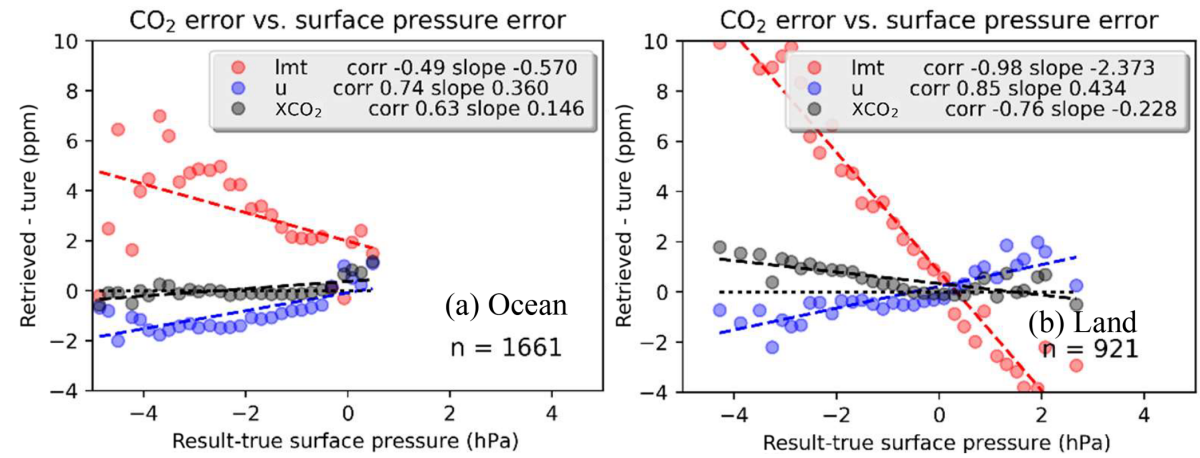

Figure 9. Error in the lower partial column (LMT), upper partial column $(U)$ and total column $\left(\mathrm{XCO}_{2}\right)$ versus error in surface pressure (with $0.2 \mathrm{hPa}$ bins) for ocean (a) and land (b). The OCO-2 $\mathrm{v} 7 \mathrm{XCO}_{2}$ bias versus $\mathrm{dP}$ is -0.3 for land and -0.08 for ocean.

mean photon path length because the path length to the surface is longer. The retrieval system varies these parameters to match the observed radiances. Ideally, the three bands would have the same albedo and aerosol properties, so that getting the $\mathrm{O} 2 \mathrm{~A}$-band mean photon path length right will also get the mean photon path length in the $\mathrm{CO}_{2}$ bands. Real aerosol optical depths tend to be higher in the $\mathrm{O} 2 \mathrm{~A}$ band than in the $\mathrm{CO}_{2}$ bands. However, the aerosol optical depth versus frequency is fixed for OCO-2. Therefore, as an example, using a too-thick aerosol in the $\mathrm{O} 2 \mathrm{~A}$ band to compensate for a too-small surface pressure will not balance in the $\mathrm{CO}_{2}$ bands because the same too-small surface pressure will be offset by less aerosol. The relative strengths of the Jacobians for the four aerosol optical depths in the $\mathrm{O} 2 \mathrm{~A}$ band versus $\mathrm{CO}_{2}$ bands are $1.5 \times, 3.3 \times, 7.2 \times$, and $2.1 \times$, respectively, indicating the dominance of the $\mathrm{O} 2 \mathrm{~A}$ band concerning aerosol information.

As seen in Fig. 8b, for $\mathrm{dP}<-2 \mathrm{hPa}$, there is a negative bias in surface pressure (because we selected for this), negative biases in three of the four aerosol optical depths (green box, parameters 1,4 , and 10), positive bias in retrieved aerosol pressure (green box, parameters $2,5,8$ ), and negative biases in the retrieved albedo (purple box, parameters 1, 3, 5). The error covariances show that (within this subset of observations) there are strong negative correlations between retrieved surface pressure error and errors in albedo and aerosol optical depth. There are also positive correlations between errors in aerosol optical depth and errors in albedo.

To trace the interferent errors to an error for $\mathrm{XCO}_{2}$, the effect of each bias on mean photon path length for the $\mathrm{O} 2 \mathrm{~A}$ band and for weak and strong bands needs to be calculated, and then the mean photon path length error of the $\mathrm{CO}_{2}$ bands versus the $\mathrm{O} 2 \mathrm{~A}$ band will give the error for $\mathrm{XCO}_{2}$. For example if the $\mathrm{O} 2 \mathrm{~A}$-band mean photon path length is perfect and the $\mathrm{CO}_{2}$ mean photon path length is $0.5 \%$ too large relative to true, then the $\mathrm{CO}_{2}$ retrieved VMR will be $0.5 \%$ too small. Since aerosols are compensating for errors in surface pressure, it is not ideal to fix their relationship versus frequency.
Figure $8 d-f$ shows the bias patterns for these different groups. Comparing Fig. 7d, e, and $\mathrm{f}$ reveals patterns that could be used for screening: e.g., a low bias in Kahn 1 aerosol optical depth and low biases in all albedo means as well as high biases in all albedo slope indicate a negative surface pressure error, whereas a high bias in Kahn 1 aerosol pressure and width and a high bias in the strong band albedo slope indicate a positive surface pressure error. In real retrievals, a high albedo bias could not be distinguished from high true albedo; however, the pattern of biases observed in Fig. 8 could be used to identify low-quality retrievals (e.g., albedo higher than expected, aerosol OD larger than expected, and surface pressure lower than expected) and implies a bad result.

It is interesting to note that the system appears to be able to compensate for and pass postprocessing quality screening, using albedo and aerosols, for low surface pressure biases down to $-4 \mathrm{hPa}$ but high surface pressure biases only up to $+2 \mathrm{hPa}$.

\subsection{Error correlation and effect of bias correction on errors}

Another important question is the following: how does bias correction within the $\mathrm{CO}_{2}$ column affect errors, particularly the error correlations in $\mathrm{XCO}_{2}$ and the partial columns? $\mathrm{Ku}-$ lawik et al. (2017) found that the predicted error correlation between the LMT and U partial columns was -0.7 for land and -0.8 for ocean, whereas the actual error correlation versus aircraft was found to be +0.6 (with uncertainty in the correlation due to the fact that aircraft do not cover the full $U$ partial column and effects of colocation error). Additionally, Kulawik et al. (2017) found that whereas the $\mathrm{XCO}_{2}$ predicted errors were underestimated by about a factor of 2 , the LMT and $U$ errors were overestimated by about a factor of 2. Weakening the LMT and $U$ correlations would result in higher and more accurate error estimates for $\mathrm{XCO}_{2}$.

The errors for $\mathrm{XCO}_{2}, \mathrm{LMT}$, and $U$ for land and ocean for configuration (b) are summarized in Table 9. The bias correc- 
Table 9. Predicted and actual errors and biases in raw and bias-corrected simulated data run with configuration (b) from Table 3. Similar to operational retrievals, bias-corrected $\mathrm{XCO}_{2}$ error is underestimated, whereas the $\mathrm{CO}_{2}$ partial column errors are overestimated. The $\mathrm{XCO}$ error underprediction results from overestimated error correlations of the partial columns.

\begin{tabular}{lrrrrrr}
\hline & $\begin{array}{r}\text { Ocean pred. } \\
(\mathrm{ppm})\end{array}$ & $\begin{array}{r}\text { Ocean actual } \\
(\mathrm{ppm})\end{array}$ & $\begin{array}{r}\text { Ocean actual } \\
\text { corrected }(\mathrm{ppm})\end{array}$ & $\begin{array}{r}\text { Land pred. } \\
(\mathrm{ppm})\end{array}$ & $\begin{array}{r}\text { Land actual } \\
(\mathrm{ppm})\end{array}$ & $\begin{array}{r}\text { Land actual } \\
\text { corrected }(\mathrm{ppm})\end{array}$ \\
\hline $\mathrm{LMT}$ & 2.6 & $2.6 \pm 2.9$ & $0.1 \pm 2.3$ & 3.3 & $2.9 \pm 4.2$ & $-0.6 \pm 2.6$ \\
$U$ & 0.9 & $-0.6 \pm 1.1$ & $0.2 \pm 1.0$ & 1.2 & $-0.6 \pm 1.4$ & $0.3 \pm 0.9$ \\
$\mathrm{XCO}_{2}$ & 0.3 & $0.1 \pm 0.7$ & $0.1 \pm 0.7$ & 0.4 & $0.2 \pm 0.8$ & $0.1 \pm 0.7$ \\
LMT and $U$ correlation & -0.91 & -0.67 & -0.57 & -0.90 & -0.68 & -0.46 \\
\hline
\end{tabular}

tion for $\mathrm{XCO}_{2}$ (using only $\delta \nabla_{\mathrm{CO}_{2}}$ and $\mathrm{dP}$ ) lowers the $\mathrm{XCO}_{2}$ bias from 0.2 to $0.1 \mathrm{ppm}$ and the error from 0.8 to $0.7 \mathrm{ppm}$ for land but has no impact on the ocean error or bias. The $\mathrm{XCO}_{2}$ error is underestimated by a factor of 2 for these simulation results, similarly to what was found with real data.

Similar to findings with real data, the $\mathrm{XCO}_{2}$ error in these simulations is underestimated, whereas the LMT and $U$ errors are overestimated. However, the overestimate of the partial column errors are not as large as seen with real GOSAT data. The predicted error correlation is -0.91 for the LMT and $U$ errors, whereas the actual error correlation is -0.5 . Using Eq. (10c) from Kulawik et al. (2017), and the LMT and $U$ errors in Table 9, we note two key results. First, the $\mathrm{XCO}_{2}$ predicted error is $0.37 \mathrm{ppm}$ when the error correlation is -0.91 . Second, the predicted $\mathrm{XCO}_{2}$ error is 0.64 $(0.71) \mathrm{ppm}$ for ocean (land) when the actual correlation is -0.57 (-0.46) for ocean (land). The second result is close to the actual error of $0.7 \mathrm{ppm}$. The estimate of +0.6 correlation from Kulawik et al. (2017) is probably wrong and could be due to unaccounted effects of colocation error on correlation estimates.

As seen in Sect. 3.1, nonlinearities from interferents affect both partial columns similarly. This would result in a positive error correlation (since the correlation is strongly negative and results in a less negative correlation than predicted) and explain the larger actual versus predicted $\mathrm{XCO}_{2}$ error. A high negative correlation is desirable for $\mathrm{XCO}_{2}$ because it asserts that, although there is uncertainty in the partitioning of LMT and $U$, the sum of the two has a smaller uncertainty.

\section{Discussion and conclusions}

The 15 orbits of simulated retrievals result in $\sim 10000$ land and ocean scenes for cloud-free runs, and 870 and 680 land and ocean cases for runs with clouds, after postprocessing quality screening. Prior to application of quality flags, described in Sect. 2.3, the errors are $\sim 10 \mathrm{ppm}$ for land and $\sim 2$ ppm for ocean. After quality flags and bias correction are applied, the errors are $0.7 \mathrm{ppm}$, with mean bias errors of $0.1 \mathrm{ppm}$ for both land and ocean. There is a spatial pattern to the bias, which has similar characteristics to the spatial pattern of real OCO-2 biases, with a correlation length of $\sim 3^{\circ}$, similar to the correlation length of $5-10^{\circ}$ for $\mathrm{OCO}-2(\mathrm{Ku}-$ lawik et al., 2019a).

Comparing runs with and without measurement noise added to the radiances showed that the predicted measurement error is accurate. Comparing the retrieved results to the linear estimate using only the $\mathrm{CO}_{2}$ parameters (smoothing error) shows that the smoothing error is not greater than $0.5 \mathrm{ppm}$, but due to interferent error and nonlinearity this could not be validated more accurately with the tests used. A more accurate way to validate this would be to run tests with different priors (e.g., Kulawik et al., 2008), which was previously done (unpublished), finding that the smoothing errors are smaller than $0.2 \mathrm{ppm}$.

The linear estimate does not predict the nonlinear retrievals to better than $0.9 \mathrm{ppm}$ (much worse when quality flags are not used), indicating this level of nonlinearity in the retrieval system. The interferent error is underpredicted by a factor of 4 , based on the relationship of $\mathrm{XCO}_{2}$ error versus error for each retrieved interferent. The retrieved interferent error is twice as large as predicted for some parameters, and the correlation between the retrieved interferent error and $\mathrm{XCO}_{2}$ error is twice as large as predicted for some parameters. The larger correlation is likely due to the fact that $\mathrm{CO}_{2}$ Jacobian strength is correlated with many retrieved interferent values; a wrong interferent value will result in the wrong $\mathrm{CO}_{2}$ Jacobian strength, resulting in an error in $\mathrm{CO}_{2}$.

Two bias correction terms are explored: $\delta \nabla_{\mathrm{CO}_{2}}$, the gradient of the retrieved $\mathrm{CO}_{2}$ profile relative to the prior state; and $\mathrm{dP}$, the retrieved surface pressure minus the prior state. The $\delta \nabla_{\mathrm{CO}_{2}}$ bias correction could be explained by the following. (1) A loose $\mathrm{CO}_{2}$ constraint near the surface prefers changes near the surface versus changes elsewhere. (2) Since the $\mathrm{CO}_{2}$ Jacobian strength near the surface is stronger versus the Jacobian elsewhere in the profile, molecules incorrectly placed near surface are underestimated, because each molecule has too much of an effect on the observed radiance. (3) This results in an $\mathrm{XCO}_{2}$ column that is too low. This explanation would explain the positive bias correction factor seen in OCO-2 v7 land and v8 land and ocean but would not explain the negative correction factor seen in v7 ocean.

The theoretical basis for $\mathrm{dP}$ is complicated because so many other retrieval parameter errors are correlated to er- 
rors in $\mathrm{dP}$. This makes sense from a fundamental radiative transfer perspective which ties together the surface and scattering properties with the amount of atmospheric column for any particular sounding. The retrieval system appears to use albedo and aerosols to compensate for errors in $\mathrm{dP}$. In these simulated results the $\mathrm{dP}$ bias correction has a similar slope as seen in real OCO-2 data for land but not for ocean. The results with $\mathrm{dP}$ errors had marginally higher radiance residuals but not high enough to easily screen.

Similar to the findings in Kulawik et al. (2017), the $\mathrm{XCO}_{2}$ column error is much higher than predicted, whereas the lower and upper partial $\mathrm{CO}_{2}$ column errors, LMT and $U$, respectively, have errors lower than predicted. The underprediction of $\mathrm{XCO}_{2}$ error results because the retrieval system thinks the LMT and $U$ partial column error correlation is -0.91 . The actual correlation is -0.5 to -0.6 after bias correction, with the uncorrected results having both higher error and higher correlations in the partial columns. When the actual correlation is used to estimate $\mathrm{XCO}_{2}$ error, the predicted $\mathrm{XCO}_{2}$ error matches the actual error within $0.1 \mathrm{ppm}$. The reason why this correlation is off may be due to the fact that both partial column Jacobian strengths vary similarly with interferent errors, which are underpredicted in the linear estimates of errors, and would result in less negative correlation between the partial columns.

These results suggest a few possible strategies (a) isolating the primary interferent parameters via preretrievals of aerosols with surface pressure, $\mathrm{CO}_{2}$, and albedo fixed, followed by a full joint retrieval. This would allow clouds and aerosols to be approximately set without throwing the other retrieved parameters off. A similar technique was employed in the thermal infrared to mitigate cloud contamination (e.g., Eldering et al., 2008). A second tactic would be to perform retrievals beginning at many different initial states, selecting the result with the lowest radiance residual. This solution however is computationally expensive.

In summary, the simulated retrievals have many of the same attributes of real data, with the advantage of knowledge of the true state and ability to see what is going on under the hood. These simulation studies suggest attention should be given to nonlinearity, because the ability to estimate errors and make incremental improvements depends on the accuracy of the linear estimate, which has an accuracy of only about $0.9 \mathrm{ppm}$ in these simulation studies.

Data availability. Data are available at https://drive.google.com/ file/d/1F_VfJOCfjlqVFLD3sY2zBjYbqPsrOVSW/view (Kulawik et al., 2019b).

Author contributions. SSK set the direction of the research, did the analysis, made figures, and was the primary manuscript writer. RRN and TET generated simulated OCO-2 true states, radiances, and retrievals. CO'D guided the work of the simulation system and ad- vised on the analysis. All authors participated in the manuscript writing and editing.

Competing interests. The authors declare that they have no conflict of interest.

Acknowledgements. Plots were made using Matplotlib (Hunter, 2007).

Financial support. This research has been supported by the NASA Roses (grant no. NMO710771/NNN13D771T, "Assessing Oco-2 Predicted Sensitivity And Errors".

Review statement. This paper was edited by Justus Notholt and reviewed by Sourish Basu and one anonymous referee.

\section{References}

Basu, S., Guerlet, S., Butz, A., Houweling, S., Hasekamp, O., Aben, I., Krummel, P., Steele, P., Langenfelds, R., Torn, M., Biraud, S., Stephens, B., Andrews, A., and Worthy, D.: Global $\mathrm{CO}_{2}$ fluxes estimated from GOSAT retrievals of total column $\mathrm{CO}_{2}$, Atmos. Chem. Phys., 13, 8695-8717, https://doi.org/10.5194/acp13-8695-2013, 2013.

Chevallier, F., Palmer, P. I., Feng, L., Boesch, H., O'Dell, C. W., and Bousquet, P.: Toward robust and consistent regional $\mathrm{CO}_{2}$ fluxestimates from in situ and spaceborne measurements of atmospheric $\mathrm{CO}_{2}$, Geophys. Res. Lett., 41, 1065-1070, https://doi.org/10.1002/2013GL058772, 2014.

Connor, B. J., Boesch, H., Toon, G., Sen, B., Miller, C., and Crisp, D.: Orbiting Carbon Observatory: Inverse method and prospective error analysis, J. Geophys. Res., 113, D05305, https://doi.org/10.1029/2006JD008336, 2008.

Connor, B., Bösch, H., McDuffie, J., Taylor, T., Fu, D., Frankenberg, C., O’Dell, C., Payne, V. H., Gunson, M., Pollock, R., Hobbs, J., Oyafuso, F., and Jiang, Y.: Quantification of uncertainties in OCO-2 measurements of $\mathrm{XCO}_{2}$ : simulations and linear error analysis, Atmos. Meas. Tech., 9, 5227-5238, https://doi.org/10.5194/amt-9-5227-2016, 2016.

Cressie, N., Wang, R., Smyth, M., and Miller, C. E.: Statistical bias and variance for the regularized inverse problem: Application to space based atmospheric $\mathrm{CO}_{2}$ retrievals, J. Geophys. Res.-Atmos., 121, 5526-5537, https://doi.org/10.1002/2015JD024353, 2016.

Crisp, D., Atlas, R. M., Breon, F.-M., Brown, L. R., Burrows, J. P., Ciais, P., Connor, B. J., Doney, S. C., Fung, I. Y., Jacob, D. J., Miller, C. E., O’Brien, D., Pawson, S., Randerson, J. T., Rayner, P., Salawitch, R. J., Sander, S. P., Sen, B., Stephens, G. L., Tans, P. P., Toon, G.C., Wennberg, P. O., Wofsy, S. C., Yung, Y. L., Kuang, Z., Chudasama, B., Sprague, G., Weiss, B., Pollock, R., Kenyon, D., and Schroll, S.: The Orbiting Carbon Observatory (OCO) Mission, Adv. Space Res., 34, 700-709, 2004. 
Crisp, D., Fisher, B. M., O’Dell, C., Frankenberg, C., Basilio, R., Bösch, H., Brown, L. R., Castano, R., Connor, B., Deutscher, N. M., Eldering, A., Griffith, D., Gunson, M., Kuze, A., Mandrake, L., McDuffie, J., Messerschmidt, J., Miller, C. E., Morino, I., Natraj, V., Notholt, J., O’Brien, D. M., Oyafuso, F., Polonsky, I., Robinson, J., Salawitch, R., Sherlock, V., Smyth, M., Suto, H., Taylor, T. E., Thompson, D. R., Wennberg, P. O., Wunch, D., and Yung, Y. L.: The ACOS $\mathrm{CO}_{2}$ retrieval algorithm - Part II: Global $\mathrm{X}_{\mathrm{CO}_{2}}$ data characterization, Atmos. Meas. Tech., 5, 687707, https://doi.org/10.5194/amt-5-687-2012, 2012.

Crisp, D., Pollock, H. R., Rosenberg, R., Chapsky, L., Lee, R. A. M., Oyafuso, F. A., Frankenberg, C., O’Dell, C. W., Bruegge, C. J., Doran, G. B., Eldering, A., Fisher, B. M., Fu, D., Gunson, M. R., Mandrake, L., Osterman, G. B., Schwandner, F. M., Sun, K., Taylor, T. E., Wennberg, P. O., and Wunch, D.: The on-orbit performance of the Orbiting Carbon Observatory-2 (OCO-2) instrument and its radiometrically calibrated products, Atmos. Meas. Tech., 10, 59-81, https://doi.org/10.5194/amt-10-59-2017, 2017.

Eldering, A., O’Dell, C. W., Wennberg, P. O., Crisp, D., Gunson, M. R., Viatte, C., Avis, C., Braverman, A., Castano, R., Chang, A., Chapsky, L., Cheng, C., Connor, B., Dang, L., Doran, G., Fisher, B., Frankenberg, C., Fu, D., Granat, R., Hobbs, J., Lee, R. A. M., Mandrake, L., McDuffie, J., Miller, C. E., Myers, V., Natraj, V., O'Brien, D., Osterman, G. B., Oyafuso, F., Payne, V. H., Pollock, H. R., Polonsky, I., Roehl, C. M., Rosenberg, R., Schwandner, F., Smyth, M., Tang, V., Taylor, T. E., To, C., Wunch, D., and Yoshimizu, J.: The Orbiting Carbon Observatory-2: first 18 months of science data products, Atmos. Meas. Tech., 10, 549563, https://doi.org/10.5194/amt-10-549-2017, 2017.

Eldering, A., Taylor, T. E., O'Dell, C. W., and Pavlick, R.: The OCO-3 mission: measurement objectives and expected performance based on 1 year of simulated data, Atmos. Meas. Tech., 12, 2341-2370, https://doi.org/10.5194/amt-122341-2019, 2019.

Eldering, A., Kulawik, S. S., Worden, J., Bowman, K., and Osterman, G.: Implementation of cloud retrievals for TES atmospheric retrievals: 2. Characterization of cloud top pressure and effective optical depth retrievals, J. Geophys. Res., 113, D16S37, https://doi.org/10.1029/2007JD008858, 2008.

Feng, L., Palmer, P. I., Parker, R. J., Deutscher, N. M., Feist, D. G., Kivi, R., Morino, I., and Sussmann, R.: Estimates of European uptake of $\mathrm{CO}_{2}$ inferred from GOSAT $\mathrm{XCO}_{2}$ retrievals: sensitivity to measurement bias inside and outside Europe, Atmos. Chem. Phys., 16, 1289-1302, https://doi.org/10.5194/acp16-1289-2016, 2016.

Frankenberg, C., Kulawik, S. S., Wofsy, S. C., Chevallier, F., Daube, B., Kort, E. A., O’Dell, C., Olsen, E. T., and Osterman, G.: Using airborne HIAPER Pole-to-Pole Observations (HIPPO) to evaluate model and remote sensing estimates of atmospheric carbon dioxide, Atmos. Chem. Phys., 16, 7867-7878, https://doi.org/10.5194/acp-16-7867-2016, 2016.

Hobbs, J., Braverman, A., Cressie, N., Granat, R., and Gunson, M.: Simulation-Based Uncertainty Quantification for Estimating Atmospheric $\mathrm{CO}_{2}$ from Satellite Data, SIAM J. Uncert. Quant., 5, 956-985, 2017.

Hunter, J. D.: Matplotlib: A 2D graphics environment, Comput. Sci. Eng., 9, 90-95, 2007.

Kulawik, S. S., Bowman, K. W., Luo, M., Rodgers, C. D., and Jourdain, L.: Impact of nonlinearity on changing the a pri- ori of trace gas profile estimates from the Tropospheric Emission Spectrometer (TES), Atmos. Chem. Phys., 8, 3081-3092, https://doi.org/10.5194/acp-8-3081-2008, 2008.

Kulawik, S. S., Crowell, S., Baker, D., Liu, J., McKain, K., Sweeney, C., Biraud, S. C., Wofsy, S., O’Dell, C. W., Wennberg, P. O.,Wunch, D., Roehl, C. M., Deutscher, N. M., Kiel, M., Griffith, D. W. T., Velazco, V. A., Notholt, J., Warneke, T., Petri, C., De Mazière, M., Sha, M. K., Sussmann, R., Rettinger, M., Pollard, D. F., Morino, I., Uchino, O., Hase, F., Feist, D. G., Roche, S., Strong, K., Kivi, R., Iraci, L., Shiomi, K., Dubey, M. K., Sepulveda, E., Rodriguez, O. E. G., Té, Y., Jeseck, P., Heikkinen, P., Dlugokencky, E. J., Gunson, M. R., Eldering, A., Crisp, D., Fisher, B., and Osterman, G. B.: Characterization of OCO2 and ACOS-GOSAT biases and errors for $\mathrm{CO}_{2}$ flux estimates, Atmos. Meas. Tech., in review, 2019a.

Kulawik, S. S., O’Dell, C., Nelson, R. R., and Taylor, T. E.: Simulations for Kulawik et al., 2019, available at: https://drive.google. com/file/d/1F_VfJOCfjlqVFLD3sY2zBjYbqPsrOVSW/view, last access: 20 September 2019b.

Kulawik, S. S., O’Dell, C., Payne, V. H., Kuai, L., Worden, H. M., Biraud, S. C., Sweeney, C., Stephens, B., Iraci, L. T., Yates, E. L., and Tanaka, T.: Lower-tropospheric $\mathrm{CO}_{2}$ from near-infrared ACOS-GOSAT observations, Atmos. Chem. Phys., 17, 54075438, https://doi.org/10.5194/acp-17-5407-2017, 2017.

Mandrake, L., O’Dell, C., Wunch, D., Wennberg, P. O., Fisher, B., Osterman, G. B., and Eldering, A.: Lite Files, Warn Level and Bias Correction Determination, 2017.

Merrelli, A., Bennartz, R., O’Dell, C. W., and Taylor, T. E.: Estimating bias in the OCO-2 retrieval algorithm caused by 3-D radiation scattering from unresolved boundary layer clouds, Atmos. Meas. Tech., 8, 1641-1656, https://doi.org/10.5194/amt-8-1641-2015, 2015.

Nelson, R. R., O’Dell, C. W., Taylor, T. E., Mandrake, L., and Smyth, M.: The potential of clear-sky carbon dioxide satellite retrievals, Atmos. Meas. Tech., 9, 1671-1684, https://doi.org/10.5194/amt-9-1671-2016, 2016.

O’Brien, D. M., Polonsky, I., O'Dell, C., and Carheden, A.: The OCO simulator Orbiting Carbon Oservatory (OCO) Algorithm Theoretical Basis Document, Cooperative Institute for Research in the Atmosphere, Colorado State University, 2009-08-13, 2009.

O'Brien, D. M., Polonsky, I. N., Utembe, S. R., and Rayner, P. J.: Potential of a geostationary geoCARB mission to estimate surface emissions of $\mathrm{CO}_{2}, \mathrm{CH}_{4}$ and $\mathrm{CO}$ in a polluted urban environment: case study Shanghai, Atmos. Meas. Tech., 9, 4633-4654, https://doi.org/10.5194/amt-9-4633-2016, 2016.

O’Dell, C. W., Connor, B., Bösch, H., O’Brien, D., Frankenberg, C., Castano, R., Christi, M., Eldering, D., Fisher, B., Gunson, M., McDuffie, J., Miller, C. E., Natraj, V., Oyafuso, F., Polonsky, I., Smyth, M., Taylor, T., Toon, G. C., Wennberg, P. O., and Wunch, D.: The ACOS CO2 retrieval algorithm - Part 1: Description and validation against synthetic observations, Atmos. Meas. Tech., 5, 99-121, https://doi.org/10.5194/amt-5-99-2012, 2012.

O’Dell, C. W., Eldering, A., Wennberg, P. O., Crisp, D., Gunson, M. R., Fisher, B., Frankenberg, C., Kiel, M., Lindqvist, H., Mandrake, L., Merrelli, A., Natraj, V., Nelson, R. R., Osterman, G. B., Payne, V. H., Taylor, T. E., Wunch, D., Drouin, B. J., Oyafuso, F., Chang, A., McDuffie, J., Smyth, M., Baker, D. F., Basu, S., Chevallier, F., Crowell, S. M. R., Feng, L., Palmer, P. I., Dubey, M., García, O. E., Griffith, D. W. T., Hase, F., Iraci, L. T., Kivi, 
R., Morino, I., Notholt, J., Ohyama, H., Petri, C., Roehl, C. M., Sha, M. K., Strong, K., Sussmann, R., Te, Y., Uchino, O., and Velazco, V. A.: Improved retrievals of carbon dioxide from Orbiting Carbon Observatory-2 with the version 8 ACOS algorithm, Atmos. Meas. Tech., 11, 6539-6576, https://doi.org/10.5194/amt11-6539-2018, 2018.

Palmer, P. I., Jacob, D.J., Chance, K., Martin, R. V., Spurr, R. D., Kurosu, T. P., Bey, I., Yantosca, Y., Fiore, A., and Li, Q.: Air mass factor formulation for spectroscopic measurements from satellites' Application to formaldehyde retrievals from the Global Ozone Monitoring Experiment, J. Geophys. Res., 106, 1453914550, 2001.

Polonsky, I. N., O’Brien, D. M., Kumer, J. B., O'Dell, C. W., and the geoCARB Team: Performance of a geostationary mission, geoCARB, to measure $\mathrm{CO}_{2}, \mathrm{CH}_{4}$ and $\mathrm{CO}$ columnaveraged concentrations, Atmos. Meas. Tech., 7, 959-981, https://doi.org/10.5194/amt-7-959-2014, 2014.

Rosenberg, R., Maxwell, S., Johnson, B. C., Chapsky, L., Lee, R. A. M., and Pollock, R.: Preflight Radiometric Calibration of Orbiting Carbon Observatory 2, IEEE T. Geosci. Remote, 55, 19942006, https://doi.org/10.1109/TGRS.2016.2634023, 2017.

Rodgers, C. D.: Inverse Methods for Atmospheric Sounding, World Scientifc, Singapore, 2000.

Taylor, T. E., O’Dell, C. W., Frankenberg, C., Partain, P. T., Cronk, H. Q., Savtchenko, A., Nelson, R. R., Rosenthal, E. J., Chang, A. Y., Fisher, B., Osterman, G. B., Pollock, R. H., Crisp, D., Eldering, A., and Gunson, M. R.: Orbiting Carbon Observatory-2 (OCO-2) cloud screening algorithms: validation against collocated MODIS and CALIOP data, Atmos. Meas. Tech., 9, 973989, https://doi.org/10.5194/amt-9-973-2016, 2016.

Winker, D. M., Pelon, J., Coakley Jr., J. A., Ackerman, S. A., Charlson, R. J., Colarco, P. R., Flamant, P., Fu, Q., Hoff, R., Kittaka, C., Kubar, T. L., LeTreut, H., McCormick, M. P., Megie, G., Poole, L., Powell, K., Trepte, C., Vaughan, M. A., and Wielicki, B. A.: The CALIPSO mission: A global 3D view of aerosols and clouds, B. Am. Meteorol. Soc., 91, 1211-1229, https://doi.org/10.1175/2010BAMS3009.1, 2010.
Wunch, D., Wennberg, P. O., Toon, G. C., Connor, B. J., Fisher, B., Osterman, G. B., Frankenberg, C., Mandrake, L., O’Dell, C., Ahonen, P., Biraud, S. C., Castano, R., Cressie, N., Crisp, D., Deutscher, N. M., Eldering, A., Fisher, M. L., Griffith, D. W. T., Gunson, M., Heikkinen, P., Keppel-Aleks, G., Kyrö, E., Lindenmaier, R., Macatangay, R., Mendonca, J., Messerschmidt, J., Miller, C. E., Morino, I., Notholt, J., Oyafuso, F. A., Rettinger, M., Robinson, J., Roehl, C. M., Salawitch, R. J., Sherlock, V., Strong, K., Sussmann, R., Tanaka, T., Thompson, D. R., Uchino, O., Warneke, T., and Wofsy, S. C.: A method for evaluating bias in global measurements of $\mathrm{CO}_{2}$ total columns from space, Atmos. Chem. Phys., 11, 12317-12337, https://doi.org/10.5194/acp-11-12317-2011, 2011.

Wunch, D., Wennberg, P. O., Osterman, G., Fisher, B., Naylor, B., Roehl, C. M., O’Dell, C., Mandrake, L., Viatte, C., Kiel, M., Griffith, D. W. T., Deutscher, N. M., Velazco, V. A., Notholt, J., Warneke, T., Petri, C., De Maziere, M., Sha, M. K., Sussmann, R., Rettinger, M., Pollard, D., Robinson, J., Morino, I., Uchino, O., Hase, F., Blumenstock, T., Feist, D. G., Arnold, S. G., Strong, K., Mendonca, J., Kivi, R., Heikkinen, P., Iraci, L., Podolske, J., Hillyard, P. W., Kawakami, S., Dubey, M. K., Parker, H. A., Sepulveda, E., García, O. E., Te, Y., Jeseck, P., Gunson, M. R., Crisp, D., and Eldering, A.: Comparisons of the Orbiting Carbon Observatory-2 (OCO-2) $\mathrm{XCO}_{2}$ measurements with TCCON, Atmos. Meas. Tech., 10, 2209-2238, https://doi.org/10.5194/amt10-2209-2017, 2017. 